NASA Technical Memorandum 104436

\title{
A Design Strategy For the Use of Vortex Generators to Manage Inlet-Engine Distortion Using Computational Fluid Dynamics
}

Bernhard H. Anderson

Lewis Research Center

Cleveland, Ohio

and

Ralph Levy

Scientific Research Associates

Glastonbury, Connecticut

Prepared for the

27th Joint Propulsion Conference

cosponsored by the AIAA, SAE, ASME, and ASEE

Sacramento, California, June 24-27, 1991

(NASA-TM-104436) A DESIGN STRATEGY FOR THE

USE OF VORTEX GENERATORS TO MANAGF

INLET-ENGINE OISTORTION USING COMPUTATIONAL

FLUID OYNAMICS (NASA) 36 $\mathrm{p}$ CSCL OLA
$N 91-24131$

Unclas 0019778 


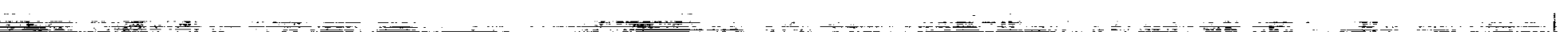

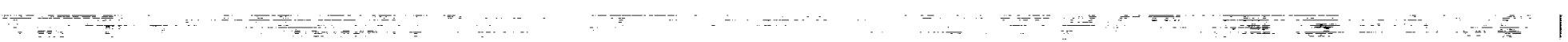

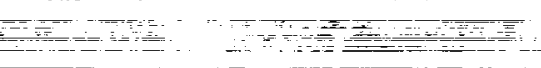




\title{
A DESIGN STRATEGY FOR THE USE OF VORTEX GENERATORS TO MANAGE INLET-ENGINE DISTORTION USING COMPUTATIONAL FLUID DYNAMICS
}

\author{
Bernhard H. Anderson \\ NASA Lewis Research Center \\ Cleveland, OH 44135 \\ and \\ Ralph Levy \\ Scientific Research Associates, Inc. \\ Glastonbury, CT 06033
}

\begin{abstract}
A Reduced Navier-Stokes solution technique has been sucessfully used to design vortex generator installations for the purpose of minimizing engine face distortion by restructuring the development of secondary flow that is induced in typical three-dimensional curved inlet ducts. The results indicate that there exists an optimum axial location for this installation of co-rotating vortex generators, and within this configuration, there exists a maximum spacing between generator blades above which the engine face distortion increases rapidly. Installed vortex generator performance, as measured by engine face circumferental distortion descriptors, is sensitive to Reynolds number and thereby the generator scale, i.e. the ratio of generator blade height to local boundary layer thickness. Installations of co-rotating vortex generators work well in terms of minimizing engine face distortion within a limited range of generator scales. Hence, the design of vortex generator installations is a point design, and all other conditions are off-design. In general, the loss levels associated with a properly designed vortex generator installation are very small, thus they represent a very good method to manage engine face distortion. This study also showed that the vortex strength, generator scale, and secondary flow field structure have a complicated and interrelated influence over engine face distortion, over and above the influence of the initial arrangement of generators.
\end{abstract}

\section{INTRODUCTION}

Modern tactical aircraft are required to be maneuverable at subsonic, transonic, and supersonic speeds, without giving up good cruise performance. Consequently, proper integration of the engine inlet with the airframe is of paramount importance. Regarding the enhancement of inlet performance and operation, design for optimum airframe-inlet integration has the following goals: (1) to minimize approach flow angularity with respect to the inlet cowl lip, (2) to deliver uniform, high pressure recovery flow to the inlet face, (3) to prevent or minimize vortex, wake, and boundary layer ingestion by the inlet throughout the flight envelope, (4) to reduce FOD hot gas ingestion by the inlet, and finally (5) to minimize the potential for flow field interference from weapon carriage'firing, landing gear deployment, tanks, pods, or other hardware. The combination of inlet design and airframe integration must not only provide high pressure recovery to maintain the desired thrust levels, but also generate low flow distortion consistent with stable engine operation.

Engine face flow distortion is one of the most troublesome and least understood problems for designers of modern inlet engine systems (Refs. 1 and 2). One issue is that there are numerous sources of flow field distortion that are ingested by the inlet or generated within the inlet duct itself. Among these sources are (1) flow separation at the cowl lip during maneuvering flight, (2) 
flow separation on the compression surfaces due to shock-wave boundary layer interactions, (3) spillage of the fuselage boundary layer into the inlet duct, (4) ingestion of aircraft vortices and wakes emanating from upstream disturbances, and (5) secondary flow and possibly flow separation within the inlet duct itself. Most aircraft have experienced one or more of these types of problems during development, particularly at high Mach numbers and or extreme maneuver conditions, such that flow distortion at the engine face exceeded allowable surge limits. Such compatibility problems were encountered in the early versions of the B70, the F-111, the F-14, the MIG-25, the Tornado and the Airbus A300 to name a few examples.

One of the most commonly used methods to control local boundary layer separation within inlet ducts entails the placement of vortex generators upstream of the problem area. Vortex generators in use today are small wing sections, mounted on aircraft wing surfaces or the inside surfaces of inlet ducts, inclined at an angle to the oncoming flow to generate a shed vortex. The generators are usually sized to local boundary layer height to allow for the best interaction between the shed vortex and boundary layer itself, and are usually placed in groups of two or more upstream of the problem area. The principle of boundary layer control by vortex generators relies on the induced mixing between the external or core stream and the boundary layer region. This mixing is promoted by vorticies trailing longitudinally over the duct surface adjacent to the edge of the boundary layer. Fluid particles with high momentum in the streamwise direction are swepted along helical paths towards the duct surface to mix with and, to some extent, replace the low momentum boundary layer flow. This is a continuous process that provides a source of reenergization to counter the natural boundary layer growth caused by friction, adverse pressure gradients, and low energy secondary flow accumulation. There are two basic configurations of vortex generators. In one configuration, all the vortex generators are inclined at the same angle with respect to the oncoming fow direction. These are called co-rotating configurations because the shed vorticies rotate in the same direction. In the other configuration, the vortex generators are grouped in pairs inclined in the opposite direction to the flow, such that pairs of counterrotating shed vorticies are generated.

Co-rotating vortex generators are very competitive in reducing flow separation if the generators are properily selected and located. The main advantage of co-rotating type vortex generators are their downstream effectiveness, resulting in more effective usage of the vortex energy within the affected boundary layer. According to design "wisdom", this type of vortex generator has a few special advantages when used within S-duct inlet configuraticins, namely: (1) the induced vortices will remain close to the wall; consequently a "cleaner" core flow will result, and (2) the induced vorticies will counteract the natural and often strong secondary flows which can deviclop.

Counter-rotating, equal strength vortex generators have been used in a number of aircraft inlet ducts, the F/A-18 and the center inlet duct on the production 727 aircrafts, to name a few examples. This type of vortex generator is very effective in reducing flow separation if the vortex generators are placed slightly upstream of the region of separation. However, according to vortex generator design "wisdom", the disadvantages of this type of generators, as compared to corotating generators, are that the induced vorticies tend to lift off the duct surface, thus reducing their effectiveness, causing higher loss in inlet recovery and larger total pressure distortion at the compressor face.

The performance of vane-type vortex generators was evaluated by Taylor (Ref. 3), for diffusers and airfoils at low speed, and by Valentine and Carrol (Refs. 4 and 5), for airfoils and wings at high speeds. This work provides trends in effectiveness for certain vortex generator design variables such as angle-of-attack, height, distance ahead of separation, etc. Attention was focused on the detailed changes that were produced in the boundary layer as a result of placement of vortex generators in the flow. Percy and Stuart (Ref. 6), extended the study of the effects of various design parameters and concluded that the strength and disposition of the individual in- 
duced vortices was more important than the details of the boundary layer upstream of the imposed pressure gradient.

In general, the design strategy adopted in these studies was basically a boundary layer approach, whereby the vortex generators provided a continuous re-energization of the boundary layer to prevent flow separation. Thus, improved engine face distortion levels were achieved by preventing local flow separation within the inlet duct. However, vortex generators within inlet ducts did not always perform as expected, primarily because the flow environment in which they were positioned was not properly taken into consideration. The "design rules" for the geometry and placement of vortex generators were based on two-dimensional boundary layer concepts, and they did not operate well in regions with high secondary flow.

It was not until the confirmation test by Kaldschmidt, Syltebo, and Ting (Ref. 7), for the refanned JT8D engine on the 727 center duct inlet that an attempt was made to use vortex generators to restructure the development of secondary flow in order to improve the engine face distortion level. Thus, a very important shift in strategy on the use of vortex generators had occurred. The perspective had moved from a local two-dimensional boundary layer approach to eliminate local flow separation, to a global three-dimensional vortex-secondary flow interaction concept, where the design goal was now to control the development of three-dimensional secondary flow itself.

In order to accomplish this new objective for internal flow control, the design strategy must shift from an experimental to an analysis based methodology. A definitive approach for computation of three-dimensional flow in curved inlet passages with vortex generator control would be the numerical solution of the full Navier-Stokes (FNS) equations. Although feasible, in three-dimensions this approach requires considerable computational effort, especially in view of the necessity of using a multi-zone strategy to resolve the very small length scales associated with the vortex generator region along with the much larger length scale phenomena associated with the inlet duct itself. A more cost effective method for predicting three-dimensional turbulent subsonic vortex flows in curved passages would be solutions to the reduced form of the NavierStokes (RIS) equations. The objective of this approach is to introduce approximations which adequately represent the essential physical processes of.interest and yet lead to governing equations which can be solved much more rconomically than the full Navier-Stokes equations.

This paper represents one in a series of studies on the design issues associated with inletengine compatibility problems. These studies center on the development of CFD tools and techniques which look promising within an analysis-design environment, and the application of these new analysis approaches to understanding and controlling inlet-engine distortion. The first paper in this series by Anderson (Ref. 8), deals with the aerodynamic characteristics of vortex interaction within the F/A-18 inlet duct, where the vortex interaction arises as a result of a vortex ingestion. Later studies will envolve the effect of vortex ingestion on the engine face flow field itself.

The overall goal of this effort is to advance the understanding and control of engine face distortion, and in particular, to analyze the basic interactions that can influence this important design problem. Specifically, the current paper achieves two goals, namely: (1) the development and validation of subsonic R. S computational techniques for analysis of general geometry inlet ducts with "real" vortex generator model capabilities, and (2) the formulation of a design strategy using CFD for the use of vortex generators to control the development of secondary flow within inlet ducts to minimize the engine face distortion. 


\section{THEORETICAL BACKGROUND}

The reduced Navier-Stokes (R.SS) equations, originally termed parabolized Navier-Stokes (PNS) equations, and more recently semi-elliptic, or partially parabolic, are used here as an initial-value space marching method for the evaluation of subsonic compressible flow with strong interactions and/or separation arising from internal vortex flows. Techniques that use space marching with an approximate form of the RNS equations, namely initial-value methods and those that require three-dimensional global iterations, have been used for a number of years to predict flows in curved ducts and turbomachinery blade cascades. Unfortunately, this terminology does not identify the relevant mathematical approximations nor does it distinguish these approximations from the properties of the solution algorithm and the differential or difference equations. In other words, different methods within the same "category" will in some instances give significantly different results.

\section{Partitioned Geometry and Mesh Generation}

Three-dimensional viscous subsonic flows in complex inlet duct geometries are investigated by a numerical procedure which allows solution by spatial forward marching integration, utilizing flow approximations from the velocity-decomposition approach of Briley and McDonald (Refs. 9 and 10). The goal of this approach is to achieve a level of approximations that will yield accurate now predictions, while reducing the labor of solution below that of the full Navier-Stokes equations. The governing equations for this approach have been given previously for orthogonal coordinates, and the approach has been applied successfully to problems whose géometries can be fitted conveniently with orthogonal coordinate systems (Ref. 11). However, geometries encountered in typical subsonic inlet ducts cannot be treated easily using orthogonal coordinates, and this lead to an extension of this approach by Levy, Briley, and McDonald (Ref. 12), to treat ducted geometries with nonorthogonal coordinates. The nonorthogonal capability has been validated over a wide range of inlet flow conditions by Towne (Refs. 13 and 14), and Anderson (Ref. $15)$.

Although the analysis itself was general, the class of ducted geometries that could be analyzed was represented by superelliptic cross-sections normal to a reference line space curve having continuous second derivatives. The description of the superelliptic cross-sections was specified by polynomials defined in terms of a marching parameter, $\tau$. In generalizing the geometry formulation Anderson (Ref. 8), extended the analysis to cover ducted geometries defined by an externally generated gridfile. This version of the 3D RNS computer code is called RNS3D. The geometry description within the gridfile is a "ducted" geometry which has a variable crosssectional area and shape and a centerline which is curved and possibly twisted. In addition, the duct described by the gridfile is considered to have a defined centerline with continouus second derivatives. The surface geometry is described in terms of cross-sectional planes which lie perpendicular to the duct centerline, and thus represent the flow area at each streamwise station. Since the inlet duct geometry definition has been reduced to a cross section specification which is placed perpendicular to a centerline space curve, then a number of grid and geometry preprocessing functions may be performed using RNS3D. These pre-processing functions include: (1) reclustering the existing gridfile mesh points distribution for more accurate solutions in regions of high shear, (2) redefining the centerline space curve to satisfy design constraints, and (3) altering the cross-sectional shape of the inlet duct to reflect specified design iterations. The approach taken by Anderson (Ref. 3), is to develop a geometry pre-processor to augment the existing geometry and grid generation programs for internal inlet duct configurations, i.e. to partition the "work" of mesh generation between the grid generator and flow solver. 


\section{Vortex Generator Model}

The model for the vortex generators within the RNS analysis, described by Kunik (Ref. 16), takes advantage of the stream function-vorticity formulation of the governing equations. The shed vortex is modeled by introducing a source term into the vorticity equation that is a function of the geometric characteristics of the generators themselves. This source term is introduced at every point in the cross-plane in the form of the following expression

$$
\Gamma_{p}=\Gamma_{0} e^{-\left(c_{1} r^{2}\right)}
$$

where $\Gamma_{0}$ is the vortex strength at any point in the crossplane, $\Gamma_{0}$ is the vortex strength at the tip of the generator, $\mathrm{r}$ is the distance between the field point and at the tip of the generator, and $c_{1}$ is a constant which controls the decay of the shed vortex strength in the crossplane. This vortex model resembles the one proposed by Squire, (Ref. 17), except that it neglects the variation of viscosity in the cross-plane. Downstream of the generator region, the analysis uses the turbulence model of McDonald and Camarata (Ref. 18), without adjustments for the influence of the generators themselves.

\section{The FLARE Approximation}

The analysis as presented here is applicable only when the primary velocity is not negative. Since "small" regions of reverse flow can arise in curved inlet ducts, the numerical method is locally modified to permit forward marching when the flow contains small regions of reverse flow. The technique used follows Reyhner and Flugge-Lotz approximation, (Ref. 19), by adding small artificial convection at grid points where the primary flow is reversed. This is known as the FLARE approximation, after the authors of Ref. 19. For thin regions of reverse flow, although the area of flow separation can be very large compared to the passage itself, the technique permits the analysis to proceed downstream beyond reattachment, confining the FLARE approximation to the separated region.

\section{Steady State Engine Face Distortion Descriptors}

It is impractical to measure anything at the engine face when the engine is installed and operating, consequently, the engine and inlet designers agreed upon an Aerodynamic Interface Plane (AIP) which is forward of the compressor face but sufficiently close to the engine face to have a similar flow field. Current U.S. practice uses forty or forty-eight transducer probes arranged in eight rakes with five or six rings. The radius of each ring is set such that all probes are at the centroid of equal areas. All distorton descriptors, whether they quantify steady state or transient distortion conditions, are always calculated relative to the standard rake located at the AIP.

The most widespread quantitative distortion descriptor available in the literature, because of its use in the earliest measurements on inlet ducts in the late 1950's, is simply:

$$
D t=\left(\frac{P t_{\max }-P t_{\min }}{P t_{\text {ave }}}\right)
$$

where $P t_{\max }$ is the maximum rake total pressure, $P t_{\min }$ is the minimum rake total pressure, and $P t_{e n}$ is the area weighted average rake total pressure. In experimental data reduction, it is assumed that the both the static pressure and temperature are constant and steady across the aerodynamic interface plane (AIP); thus both the velocity and Mach number can be considered functions only of total pressue and the distribution of this quantity is the only measurement that needs to be made. This parameter is always useful to determine for comparison purposes and to describe the 'general health' of inlet ducts irrespective of the type of powerplant that may be used. 
The effect of circumferential distortion on compressor surge margin is essentially to drop the maximum pressure ratio of a constant corrected speed line. One of the simplest quoted descriptor for circumferential distortion is from Rolls Royce and is defined as

$$
D C_{\theta}=\left(\frac{P t_{\text {ave }}-P t_{\min }}{q_{\text {ave }}}\right)
$$

where $P t_{\text {eve }}$ and $q_{\text {ove }}$ are the average total and dynamic pressure at the engine face or aerodynamic interface plane and $P t_{\min }$ is the mimimum total pressure in any pi-section of extent $\theta$. Significant $\theta$ values can vary with engine design and commonly are $60^{\circ}, 90^{\circ}$, and $120^{\circ}$. For bypass engines, a circumferential distortion descriptor $D C_{0-G G}$ is often used, where $G G$ indicates that the index is taken over the area of the gas generator.

More advanced distortion descriptors, introduced in the late 1960's and 1970's, take into account the $D t$ distortion of each ring of total pressure measurements. Thus, the radial distortion $D t$, is defined as

$$
D t_{r}=\left(\frac{P t_{\max }-P t_{\text {ave }}}{P t_{\max }}\right)_{r i n g}
$$

where $P t_{\text {ave }}$ is the average total pressure for a given ring radius and $P t_{\max }$ is the maximum local ring total pressure. The circumferential distortion $D t_{\theta}$ is defined as:

$$
D t_{\theta}=\left(\frac{P t_{\text {ave }}-P t_{\text {min }}}{P t_{\text {ave }}}\right)_{\text {ring }}
$$

where $P t_{\min }$ is the lowest average total pressure in any $\theta$ segment, usually $60^{\circ}$ or $180^{\circ}$ of arc for a given ring radius having an average ring total pressure $P t_{\text {ave. }}$. The ring distortion descriptors $D t_{r}$ and $D t_{\theta}$ are both functions of engine face radius, and will be expressed in terms of normalized engine face radius, i.e.,

$$
\delta_{e f}=\left(\frac{r-r_{\text {dome }}}{r_{\text {cowl }}-r_{\text {dome }}}\right)
$$

where $r$ is the engine face field point radius, $r_{\text {dome }}$ is the radius of the engine dome, and $r_{\text {com }}$ is the engine cowl radius.

\section{RESULTS AND DISCUSSIONS}

\section{Comparison and Validation with Experimental Data}

To demonstrate the accuracy of the numerical results obtained with RNS3D for internal duct flows typical of high angle-of-attack conditions, a series of numerical simulations were carried out using the University of Tennessee diffusing S-duct. In this experimental investigation sponsored by $\mathrm{NASA}$ Lewis Research Center Vakili, Wu, Liver, and Bhat (Ref. 20), obtained a series of measurements in a 30-30 degree diffusing S-duct of area ratio 1.5 with and without vortex generators (Fig. 1). The 30-30 degree circular cross-section S-duct, shown in Fig. 1, was made from two symmetric sections. The inlet duct diameter $D_{1}$ was $16.51 \mathrm{~cm}$. and duct cenerline had a mean radius of curvature $\mathrm{R}$ of $82.55 \mathrm{~cm}$. A straight pipe section of length $4.75 D_{i}$ was installed upstream of the curved section to allow for the development of the turbulent boundary laver to the desired thickness. Another pipe of length $9.0 D_{e}$ was installed downstream of the $S$. duct.

All measurements were made at a nominal inlet Mach number of 0.60 at the reference measurement station in the straight section at $X / D_{t}=-1.54$. The low parameters at this station 
were used as reference conditions for non-dimensionizing the experimental data. The experimental survey stations correspond to $X_{i} D_{i}=0.0,1.29,2.49$, and 5.2. At each survey station, a five-port cone probe was traversed radially at ten azimuthal angles, approximately 20 degrees apart, on both sides of the symmetry plane. At least seventy points were measured at each traverse.

A polar grid topology (Fig. 2) was chosen for the University of Tennessee diffusing S-duct, consisting of 49 radial, 49 circumferential, and 101 streamwise nodal points in the half-plane. The internal grid was constructed such that the transverse computational plane was perpendicular to the duct centerline. Grid clustering was used both in the radial and circumferential directions to redistribute the nodal points along these coordinate lines to resolve the high shear region near the wall and the separation region in the second bend. The flow in the duct was turbulent, with an entrance Mach number of 0.6 , Reynolds number based on hydraulic diameter of $1.76 \times 10^{6}$, and a shear layer thickness of $\delta D_{i}=0.05$. These initial conditions were applied at approximately an axial station 1.54 inlet diameters $\left(D_{i}\right)$ upstream of the duct entrance.

Fig. 3 shows a comparison between the experimental and computed total pressure coefficient contours at $\mathrm{X}: D_{i}=5.2$. In both the experiment and analysis, the flow in the $S$-duct separated and reattached in the second bend upstream of $X / D_{i}=5.2$. This flow separation was caused by both adverse streamwise pressure gradient and the effect of pressure-driven secondary flow resulting from duct curvature. Experimental measurements and computational results from the $3 D$ R.S code include the phenomena of separation and reattachment upstream of $X_{i}^{\prime} D_{i}=5.2$ and show excellent agreement for a simple mixing length turbulence model.

As separation was encountered in the second bend of the S-duct, three pairs of vortex generator devices were installed in the duct at $\mathrm{X} / D_{i}=0.09$, and at circumferential angles of -38.0 , 0.0 , and +38.0 degrees. The vortex generator pairs had geometric incidence angles of +16.0 and -16.0 degrees relative to the duct centerline. Fig. 4 shows the comparison between the experimental and computed total pressure coefficient contours at $\mathrm{X} / D_{i}=5.2$. Comparison of contour levels between the separated case (Fig. 3), and the vortex generator case (Fig. 4), shows that the vortex generators successfully mixed the high energy core flow with the low energy flow in the wall region to suppress separation. In general, the computed interaction between the induced vortex generator flow and the pressure driven secondary flow was physically realistic and the agreement between experiment and analysis is considered very good, although morz improvements on the generator model must be made.

Figs. 5 and 6 show additional flow characteristics obtained with the 3D RNS analysis with the vortex generator modeling. The secondary flow structure from the vortex generator model just downstream of the generator region, i.e. at $X / D_{i}=0.18$ is shown in Fig. 5 , and clearly reveals the three pairs of vortices that arise from the three pairs of counter-rotating generators. The limiting streamline signature shown in Fig. 6 indicates that the generator configuration tested eliminated the flow separation encountered in the second bend, and reveals the familiar topographical pattern through the generator region itself.

\section{Flow Separation and Vortex Liftoff}

The three-dimensional separation encountered in the University of Tennesse diffusing Sduct was very large in area and thin in extent (Figs. 7 and 8), and this separartion did not altered the pressure distribution in a substantial manner. Secondary flow resulting from duct curvature caused an accumulation of boundary layer near the innerwall of the first 30 degree bend. The thick boundary layer thus established was especially susceptible to flow separation because of the adverse streamwise pressure gradients induced by the reverse curvature section of the second 30 degree bend. A comparison between the computed oil now patterns (represented by the limiting streamline topology in Fig. 7) and the experimental oil flow patterns presented in Fig. 8 shows excellent correspondence. Of exceptional importance is the fact that the space marching R.IS 
analysis method using FLARE approximations captures the reverse flow region of this separation.

To meet the required confidence level of code validation, it is also essential that the 3D RNS marching analysis be able to capture the known topological structure of the limiting streamlines in the vicinity of a three-dimensional separation. A very striking and significant feature captured by the analysis (Fig. 9), and seen in the oil flow pattern (Fig. 8), is the convergence of the limiting streamlines as an indication of three-dimensional separation taking place in this duct. Another important and striking feature is the symmetric pair of spiral nodes and pair of saddle points that were clearly captured by the 3D RNS analysis. The topological patterns, as shown in the analy'sis Fig. 9, and the photograph of the surface oil flow pattern Fig. 8, also reveal the remarkable characteristic that the limiting streamlines forming the spiral node enter only from downstream of the nodal point. The very familiar topological pattern shown in Figs. 7 and 8 is known to describe the important stage in the development of the pair of counter-rotating vortices that form in the first 30 degrees of turning resulting in vortex liftoff in the second bend.

\section{The Design Problem Using Vortex Flow Control}

Unlike external aerodynamics where the two-dimensional flow assumption is valid over extended regions of the flow field, the internal flow problem is plagued with three-dimensional now effects. When viscous effects or other sources of vorticity are present, three-dimensional flows differ fundamentally from their two-dimensional counterparts in that large secondary flows are generated by a deflection of the primary flow and/or other mechanisms. Secondary flow theory (reviewed by Horlock and Lakshminaryana Ref. 21, and Lakshminarayana and Horlock Ref. 22) affords considerable insight into the generation of secondary flow and establishes that large secondary flows can be generated by small deflections of vorticity or shear. The large secondary flows thus generated often exert an appreciable influence on the primary flow, and thus aerodynamic performance, viscous losses, and engine face distortion can be significantly affected. Therefore, the design problem is to control the three-dimensional secondary flows that are generated within typical inlet ducts through an arrangement of vortex generators for the purpose of minimizing engine face distortion, and the effectiveness of the the design is judged by standard engine distortion descriptors.

\section{Inlet Duct and Vortex Flow Control Design Variables}

The 727:JT8D-100 center inlet duct geometry and computational grid used in this study is shown in Fig. 10, and the single block polar cross-sectional grid topology, with 99 radial and 49 circumferential grid points in the half-plane is presented in Fig. 10 at two axial stations, i.e. at $X / R_{i}=0.0$ and $X / R_{i}=5.0$. The computation were made at an inlet enterence Mach number of 0.6 , Reynolds number of $12.0 \times 10^{6}$ based on hydraulic inlet diameter $\left(D_{i}\right)$, and a shear layer thickness $\delta / D_{i}=0.005$.

The geometry of the co-rotating vortex generators used in this study along with the nomenclature used in positioning the individual blades are presented in Figs. (11) and (12). The important geometric design parameters include: (1) the vortex generator blade height $\left(h / R_{i}\right),(2)$ the blade chord length $\left(c / R_{i}\right)$, and (3) the vane angle of attack $\left(\beta_{v g}\right)$. For all the calculations within this study, the vortex generator blade height $\left(h / R_{t}\right)$ was set a 0.075 , the ratio of generator height to chord length $(h / c)$ was fixed at 0.5 , and the vane angle of attack $\left(\beta_{v g}\right)$ was set at $16.0^{\circ}$. Instead of the usual spacing parameter $\left(d / R_{i}\right)$, i.e. the distance between adjacent blades, the positioning of the vortex generator blades was described in terms of a spacing angle $\left(\alpha_{v g}\right)$ and a sector angle over which the blades were positioned $\left(\theta_{s}\right)$. For this study, the relationship between blade spacing angle $\left(x_{. s}\right)$ and sector angle $\left(\theta_{s}\right)$ is given by

$$
\theta_{s}=\alpha_{v g}\left(n_{v g}-\frac{1}{2}\right)
$$


where $\left(n_{v g}\right)$ is the number of vortex generator blades. Equ. (7) was also used to position the individual generator blades around the inside periphery of the inlet duct at a given axial sector location $\left(X_{b g} / R_{i}\right)$. The angle $\left(\theta_{s}\right)$ was measured counter-clockwise relative to an azimuthal angle of $180^{\circ}$ with respect to the vertical axis of the duct.

Shown in Fig. 13 are the axial locations of the vortex generator sector regions $\left(X_{n z} / R_{i}\right)$ covered in this study. These sector regions were located between $X_{v g} / R_{i}=2.0$ and $X_{v g} / R_{i}=7.0$, and cover a sector angle $\left(\theta_{s}\right)$ up to $157.5^{\circ}$ as measured counter-clockwise relative to an azimuthal angle of $180^{\circ}$ with respect to the vertical axis of the duct.

Tables I, II, and III present the range of vortex generator configurations, or test cases, considered for this study, and these have been arranged in five different groupings. In the first grouping, i.e. Configs. 1 through 4 , the effect of vortex generator sector angle $\left(\theta_{s}\right)$ was investigated at a sector location $\left(X_{v g} / R_{i}=3.0\right)$, for a fixed spacing angle, $\alpha_{v g}=15.0^{\circ}$. In the second grouping, i.e. Configs. 5 through 10 , the influence of vortex generator sector location $\left(X_{v z} / R_{i}\right)$ was investigated for a fixed spacing angle $\left(\alpha_{v_{2}}\right)$ and sector angle $\left(\theta_{s}\right)$ of $15.0^{\circ}$ and $127.5^{\circ}$ respectively. The third grouping, i.e. Configs. 11 through 14 , investigated the effect of vortex generator spacing angle $\left(\alpha_{\mathrm{kg}}\right)$, keeping the generrator sector angle $\left(\theta_{s}\right)$ fixed at $127.5^{\circ}$, and the sector location fixed at $X_{r_{g}} / R_{i}=5.0$. In the forth grouping. i.e. Configs. 15 through 18 , the effect of generator sector angle was repeated, but at the axial sector location $X_{v z} / R_{i}=5: 0$. The last grouping of configurations was intended to show the effect of Reynold's number on the installed vortex generator performance.

\section{Distortion and Vortex Interactions with Secondary Flow}

In order to design a system of generators for vortex flow control which remains effective over a wide range of operating conditions, it becomes important to understand the effect of Reynold's number on engine face distortion as measured by standard distortion descriptors. Presented in Figs. 14 and 15 is the effect of Reynold's number on the radial pressure and $60^{\circ}$-sector circumferential pressure ring distortion respectively, as defined by Equs. (4.0) and (5.0). The advantage of expressing distortion in terms of a ring descriptor is that the distribution of both radial and circumferential distortion can be quantified and tracked as a function of engine face radius. It is evident that the low enersy region associated with the induced vortex pair enlarges between a Reynolds number of $16.0 \times 10^{6}$ and $4.0 \times 10^{6}$ (Fig. 14), and that this enlargement was accompanied by an increase in the peak $60^{\circ}$-sector circumferential ring distortion from 0.045 to 0.082 (Fig. 15). In addition, peak $60^{\circ}$-sector circumferential distortion is moving radial towards the engine face centerline as the Reynold's number decreases.

Presented in Figs. 16 through 20 are various aspects of vortex interactions with the secondary flow generated within the 727, JT8D-100 center inlet duct induced by the vortex generator installations defined in Tables I through III. All of these interaction are described in terms of the $60^{\circ}$-sector circumferential ring distortion descriptor, which is a function of the engine face radius. The effect of sector angle on engine face circumferential distortion (Configs. 1 thru 4 ) is presented in Fig. 16, while the influence of sector location (Configs. 5 thru 10) is presented in Fig. 17. In each of these cases, the vortex generator height and generator vane angle of attack were held fixed, along with the number of vortex generators and spacing angle. Thus, for this installation of vortex generators, there is an optimum axial sector location, between 5.0 and 6.0 ,. which will minimizes the $60^{\circ}$-sector circumferential distortion. This phenomenon will be discussed in greater detail in the next section.

Choosing the axial sector location of 5.0 as the optimum station for this installation of co-rotating vortex generators, Fig. IS and 19 present the effects of spacing angle and sector angle on the $60^{\circ}$-sector circumferential ring distortion as a function of engine face radius. These installations of generators are Configs. 11 thru 14 and 15 thru 18. 
The effect of Reynold's number on the installed performance of vortex generator Config. 8 , as measured by the $60^{\circ}$-sector circumferential pressure ring distortion descriptor, is presented in Fig. 20. The vortex generators installation was designed at a Reynold's number of $12.0 \times 10^{6}$, and it is quite apparent that the minimum distortion occurs at this condition. Note also the significant difference in both the level and shape of the the distortion signature as a function of engine face radius. The Reynolds number effect on installed vortex generator performance will be examined in greater detail in the following section.

\section{Design Characteristics of Co-Rotating Generators for Vortex Flow Control}

Figs. 22 through 33 present a summary of the installed performance of vortex generator configurations 1 through 22 in terms of the engine face average total pressure recovery $\left(\bar{P}_{t} f P_{t_{0}}\right)$ and the "peak" or maximum $60^{\circ}$-sector circumferential ring distortion descriptor that were presented in Figs. 14 thru 20. Also included on these figures are the engine face total pressure recovery maps for each of the cases considered in this study. The engine face total pressure recovery $\left(P_{t} / P_{t_{0}}\right)$ is presented both as a mass flow averaged value over the cross-sectional computational mesh, which was composed of 99 radial and 49 circumferential points in the half plane, and as area averaged value over a standard 40-probe rake. The standard 40-probe rake characteristics were included in this this study in order to determine whether this rake is sufficant to be used for vortex generator experiments. Bear in mind that because the computations were performed in the half-plane, the 40-probe standard rake compares with 9,702 computational mesh points in the plane of the engine face. A schmatic diagram of a 40-probe standard rake showing the individual probe locations is presented in Fig. 21.

The effect of Reynolds number on engine face total pressure recovery and peak $60^{\circ}$-sector circumferential pressure ring distortion is presented in Figs. 22 and 23 for the baseline configuration without vortex fow control. There is a significant decrease in the total pressure recovery, from 0.982 to 0.979 , and an increase in the maximum circumferential pressure ring distortion, from 0.045 to 0.087 , over the Reynolds number range from $16.0 \times 10^{6}$ to $4.0 \times 10^{6}$. Note also that. area averaged engine face total pressure recovery using a standard 40 -probe rake poorly represents both the level and trends of this Reynolds number phenomenon.

Presented in Figs. 24 and 25 is the effects of vortex generator sector angle on engine face total pressure recovery and maximum $60^{\circ}$-sector circumferential pressure ring distortion at a axial sector location of 3.0 , and generator spacing angle of $15.0^{\circ}$. As the number of vortex generators is increased, at a constant spacing angle, the sector angle angle increases according to Equ. (7), and this has the effect of decreasing the peak $60^{\circ}$-sector circumferential ring distortion as shown in Fig. 25. Since there are a discrete number of generators that can be placed around the inside periphery of the inlet duct, a minimum distortion will occure at a sector angle of $180^{\circ}$.

Figs. 26 and 27 presents the effect of vortex generator sector location on the average engine face total pressure recovery and the peak $60^{\circ}$-sector circumferential pressure ring distortion. For the installation of co-rotating vortex generators defined by Configs. 5 thru 10 in Tabel I, the optimum axial location lies between 5.0 and 6.0 , and the overall circumferential distortion within this range of axial positions is less than 0.01 . Thus, for a given co-rotating vortex generator installation, there exists an axial position within the inlet duct which provides a minimum engine face circumferential distortion.

Presented in Figs. 28 and 29 are the engine face average total pressure recovery and the maximum $60^{\circ}$-sector circumferential ring distortion for vortex generator Configs. 11 through 14 . As the vortex generators spacing angle increases, (by decreasing the number of vortex generators while keeping the sector angle fixed at $127.5^{\circ}$ ), the maximum $60^{\circ}$-sector circumferential ring distortion increases very rapidly above $20.0^{\circ}$. Thus, there exists a maximum spacing of vortex generator blades above which the engine face circumferential distortion increases very rapidly. This suggests a dramatically different design guideline for vortex generator installations from that in 
Ref. 6 , but bear in mind that the effectiveness parameter used by Percy was retention of the individual vortex identities downstream of the generator blades as measured on a flat plate, while the effectiveness indicator used in this study was the maximum $60^{\circ}$-sector circumferential distortion. Increasing the vortex generator spacing angle does indeed increase the retention of the individual vortex identities, as can clearly be seen from the series of compressor face total pressure maps presentd in Fig. 29, however, while this design guideline is good for supressing local flow separation, it actually increases the circumferential distortion index. There was a primary flow separation in the baseline $727, \mathrm{JT} 8 \mathrm{D}-100$ inlet, both in the experimental and computational duct, and this separation was associated with vortex liftoff. Each of the vortex generators installations presented in Fig. 29 supressed this local flow separation. However, if a circumferential distortion descriptor is used as the measure of effectiveness, then it is desirable to have closer spacing between vortex generators than would normally be used to supress local flow separation.

The effect of the vortex generator sector angle on the maximum $60^{\circ}$-sector circumferential pressure ring distortion at an axial sector location of 5.0, (Configs. 15 thru 18 in Table II), is presented in Figs. 30 and 31 . The relationship between number of vortex generators and the sector angle for a fixed spacing angle is again given by Equ. (6.0). In comparison with a similar study done at the axial sector location of $3.0 \mathrm{Fig}$. 25 , it is clear that this installation of co-rotating generators is best located at an axial location of 5.0. Had another installation of generators with different physical dimensions been chosen, then a different optimum axial sector location would have resulted.

The effect of Reynolds number on engine face recovery and distortion for the vortex generator Config. 8 is presented in Figs. 32 and 33 . For this installation of vortex generators, the average total pressure recovery level $\left.\left(\bar{P}_{t_{e}}\right) P_{t_{0}}\right)$ and maximum $60^{\circ}$-sector circumferential pressure ring distortion index remain reasonably level between the Reynolds numbers of $16.0 \times 10^{6}$ and $8.0 \times 10^{6}$. For Reynolds number less than $8.0 \times 10^{6}$ the flow at the engine face "breaks" down and the distortion increases very rapidly. The systematic and continuous nature of the flow field breakdown can be seen in the engine face total pressure recovery maps presented in Fig. 33 . Installed vortex generator performance, as measured by standard engine face circumferential distortion descriptors, is sensitive to Reynolds number and thereby the generator scale, i.e. the ratio of generator blade height to local boundary layer thickness. Installations of co-rotating vortex generators work well in terms of minimizing engine face distortion within a limited range of generator scales. Clearly this effect is not well understood since it may be influenced by the structure and strength of the induced secondary now. Consequently, this is an area for future research. However, it is important to recognize that the design of the vortex generator installation is a point design, and all other conditions are off-design.

Comparison with the 727/JT8D-100 Comformation Test Data

The Phase II low speed conformation tests on the 727/JT8D-100 center inlet duct performed by Kaldschmidt, Syltedo, and Ting Ref. 7, were sponsored by NASA Lewis Research Center and performed in the Boeing $9 \mathrm{ft}$. $x 9 \mathrm{ft}$. low speed wind tunnel between July and November of 1973. This series of experiments were performed as a conformation test for a redesigned center inlet duct for the $727-100$ series aircraft, and they were never meant to be used as validation for computationsl codes. As such, the information presented in Ref. 7 is incomplete for code validation, however the data is valuable enough to attempt a comparison with computations using R.SS3D. It must be understood that much of the input information was estimated or gleaned from figures or photographs presented in Ref. 7 , and do not represent precise values.

The experimental and computed engine face total pressure contours for the 727. JT8D-100 baseline duct without vortex generators is shown in Fig. 34. The experimental model had an engine nose dome of elliptical shape of aspect ratio 2.0 , while the calculations were performed without the dome for simplicity. In general, the comparision between analysis and experiment is quite good, bearing in mind that the exact tunnel conditions were not specified in Rer. 7, nor 
is the influence of the nose dome understood. The effect of the nose dome on the engine face total pressure recovery map and distortion level has never been systematically studied, but some performance advantage might be gained since the circumferential distortion descriptors are very sensitive to both level and distribution.

Fig. 35 present a comparision between the engine face total pressure map with the "best" experimental vortex generator installation (Config. 12 in Ref. 7), and RNS3D results with the generator pattern which can be gleaned to be most similar to the experimental installation (Config. 3 in Table I). Both vortex generator installations were composed of seven pairs of corotating generators assumed to be symmetrically located about the $180^{\circ}$ azimuthal reference, and positioned at an axial location of 3.0. However, the experimental generator installation also contained three pairs of counter-rotating generators located symmetrically about the $0.0^{\circ}$ azimuthal reference, and positioned just upstream of the engine face, while the calculations did not include any counter-rotating generators. In general, calculations of the vortex generator flow field, and in particular the engine face total pressure distortion map, shows remarkable agreement with the measured engine face recovery map.

Presented in Fig. 36 is a comparison between the engine face recovery maps resulting from the experimental vortex generator installation judged the most effective (Config. 12 in Ref. 7 ) and the computational generator installation judged most effective (Config. 15 in Table II). The computational vortex generator installation was composed of eleven pairs of co-rotating generators located at an axial sector location of 5.0. While the computational vortex generator installation had one additional pair of generators over the experimental configuration, the additional loss associated with this pair will be remarkable small as indicated in Table IV. The measured loss level resulting from ten pairs of vortex generators is 0.002 as presented in Ref. 7 , thus the loss level associated with the additional pair will be very small. The loss levels associated with properly design vortex generators installations are in general very small, and thus they represent a very good method to manage engine face distortion by restructuring the development of the secondary flow that is induced within three-dimensional curved inlet ducts.

\section{CONCLUSIONS}

The present results provide a validation of the initial value space-marching 3D RNS procedure and demonstrate accurate predictions of the compressor face flow field, with a separation present in the inlet duct as well as when vortex generators were installed to suppress separation. The computing time on the CRAY XMP (i.e., CPU $=6.5 \mathrm{~min}$. for $2.28 \times 10^{5}$ grid points) for University of Tennessee diffusing $S$-duct configuration for both the baseline and the the case with three pairs of counter-rotating vortex generators, is sufficiently rapid for routine use in an analysis and design environment.

This paper demonstrates that the three-dimensional Reduced Navier-Stokes code RNS3D can be used very effectively to develop a vortex generator installation for the purpose of minimizing engine face distortion by restructuring the development of secondary flow induced in typical three-dimensional curved inlet ducts. For a given installation of vortex generators, there exists an axial location within the inlet duct which will minimize engine face distortion, and within this installation, there exist a maximum spacing of generators above which the distortion increases rapidly. The installed performance of vortex generators is sensitive to Reynolds number or generator scale, i.e. the ratio of blade height to local or average boundary layer thickness. Consequently, there is a limited range of generator scales that serve to minimize engine face distortion. Therefore, the design of vortex generator installation is a point design and all other conditions are off-design. In general, the loss level associated with a properly designed installation of vortex generators is very small, and thus they represent a very good method to manage engine face distortion. This study also shows that the vortex strength, generator scale, and secondary flow field structure have a complicated and interrelated influence on the engine face distortion, over and above the influence of the initial arrangenent of generators. 


\section{REFERENCES}

1. Advisory Group for Aerospace Research and Development (AGARD), "Engine Response to Distorted Inflow Conditions," AGARD CP-400, Sept., 1986.

2. Bowditch, D. N. and Coltrin, R. E., "A Survey of Inlet/Engine Distortion Compatability," AIAA-83-1166, June 1983.

3. Taylor, D., "Application of Vortex Generator Mixing Principle to Diffusers," U.A.C. Rep. R-15064-5, Dec. 1948.

4. Valentine, E. F. and Carrol, R. B., "Effects of Several Arrangements of Rectangular Vortex Generators on the Static Pressure Rise Through a Short 2:1 Diffuser," NASA RM L50L04, Feb. 1951.

5. Valentine, E. F. and Carrol, R. B., "Effects of Some Primary Variables of Rectangular Vortex Generators on the Static Pressure Rise Thrcugh a Short Diffuser," NACA R.M 52B13, May 1952.

6. Pearcy, H. H. and Stuart, C. M., "Methods of Boundary-Layer Control for Postponing and Alleviating Buffeting and other Effects of Shock-Induced Separation," Presented at the IAS National Summer Meeting, Los Angles, Calf., June, 1959.

7. Kaldschmidt, G., Syltedo, B. E., and Ting, C. T., "727 Airplane Center Duct Inlet Low-Speed Performance Confirmation Model Test for Refanned JT8D Engines - Phase II," NASA CR-134534, . Nov. 1973.

8. Anderson, Bernhard H., "The Acrodynamic Characteristics of Vortex Ingestion for the F/A-18 Inlet Duct," AIAA Paper No. 91-0130, AIAA 28th Aerospace Sciences Meeting, Jan. 1991.

9. Briley, W. R. and McDonald, H., "Analysis and Computation of Viscous Subsonic Primary and Secondary Flow," AIAA Paper No. 79-1453.

10. Briley, W. R., and McDonald, H., "Three-Dimensional Viscous Flows with Large Secondary Velocities," Journal of Fluid Mechanics, March 1984, vol. 144, pp. 47-77.

11. Kreskovsky, J. P., Briley, W. R. and McDonald, H., "Prediction of Laminar and Turbulent Primary and Secondary Flows in Strongly Curved Ducts," NASA CR-3388, Feb. 1981

12. Lery, R., Briley, W. R., and McDonald, H., "Viscous Primary 'Secondary Flow Analysis for Lise with Nonorthogonal Coordinate Systems," AIAA Paper No. 83-0556, Jan. 1983.

13. Towne, C. E., and Anderson, B. H., "Numerical Simulation of Flows in Curved Diffusers with Cross-Sectional Transitioning Ling a Three Dimensional Viscous Analysis," AIAA Paper No. \$1-0003, Jan. 1981.

14. Towne, C. E., "Computation of Viscous Flow in Curved Ducts with Experimental Data," AIAA Paper No. S4-0531, AIAA 22th Aerospace Sciences Meeting, Jan. 1984.

15. Anderson. B. II., "Three Dimensional Viscous Design Methodology of Supersonic Inlet Systems for Advanced Technology Aircraft," Numerical Methods for Engine-Airframe Integration, American Institute of Aeronautics and Astronautics Series, 1986. 
16. Kunik, W. G., "Application of a Computational Model for Vortex Generators in Subsonic Internal Flows," AIAA Paper No. 86-1458, June 1986.

17. Squire, R., "Growth of a Vortex in Turbulent Flow," The Aeronautical Quarterly, Vol. 16, Pt. 3 , August 1965, pp 302-306.

18. McDonald, H. and Camarata, F. J.: "An Extended Mixing Length Approach for Computing the Turbulent Boundary-Layer Development, Proceedings, Standford Conference of Turbulent Boundary Layers," Vol. I, Pub. by Stanford University, pp. 83-98, 1969.

19. Reyner, T. A. and Flugge-Lotz, I., "Interaction of a Shock Wave with a Laminar Boundary Layer," International Journal of Non-Linear Mechanics, Vol. 3, 1968.

20. Vakili, A. D., Wu, J. M., Liver, P. A., and Bhat, M. K., "Experimental Investigation of Secondary Flows in a Diffusing S-Duct with Vortex Generators," NASA NAG3-233, July, 1986.

21. Horlock, J. H. and Lakshminaravana, B., "1973 Secondary Flows: Theory, Experiment, and Applications in Turbomachinery Aerodynamics," Ann. Rev. Fluid Mechanics, Vol 5, pp 247-280.

22. Lakshminarayana, B, and Horlock, J. H., "Generalized Expressons for Secondary Vorticity Using Intrinsic Coordinates," J. Fluid Mechanics. Vol. 59, pp 97-115. 


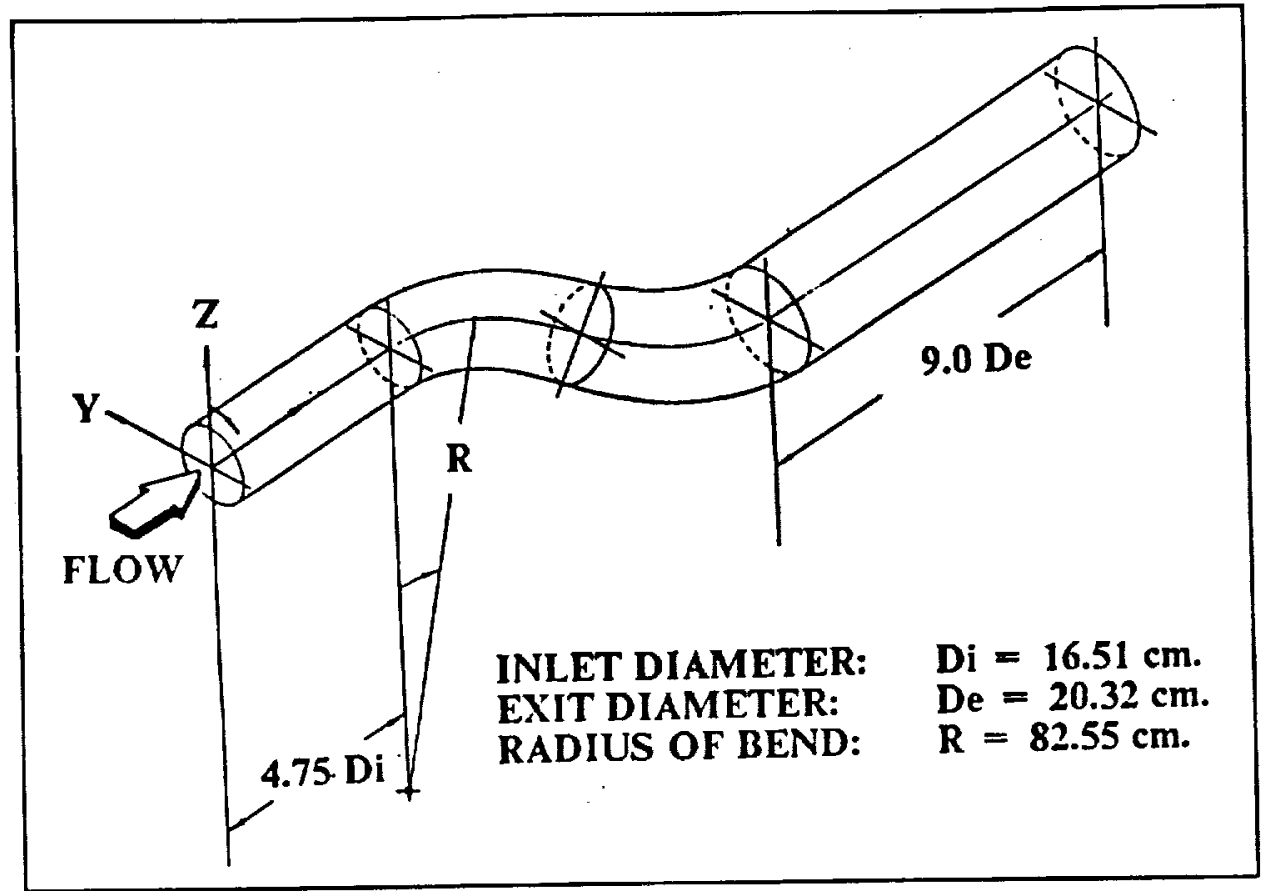

Figure (1) - Geometry definition of the Univ. Tennessee diffusing S-duct.

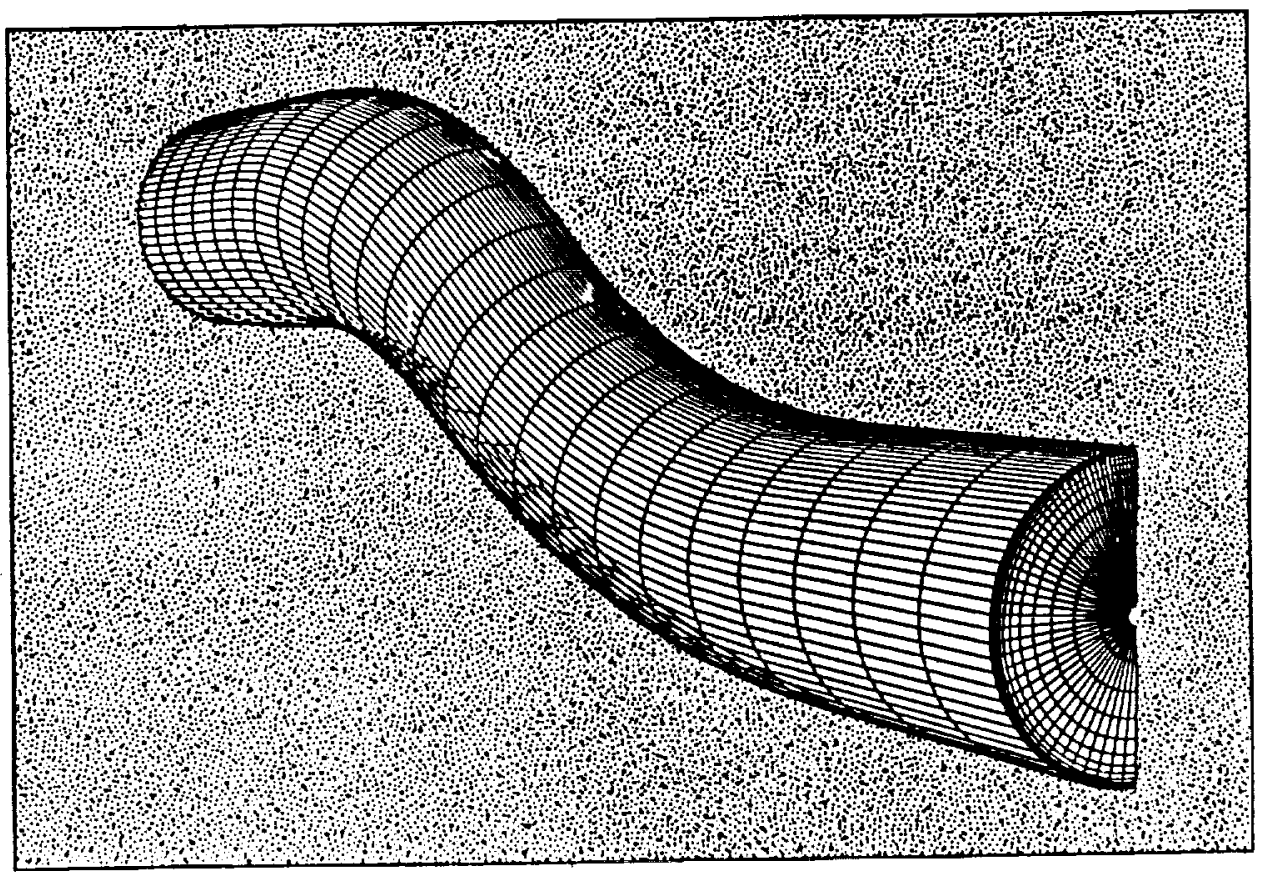

Figure (2) - Computation grid for the Univ. Tennessee diffusing S-duct. 


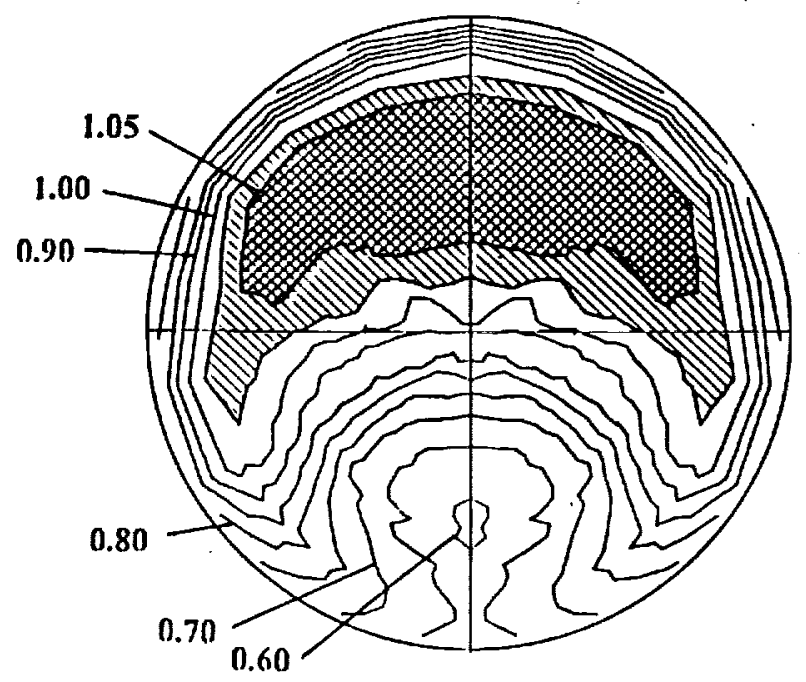

EXPERIMENTAL DATA

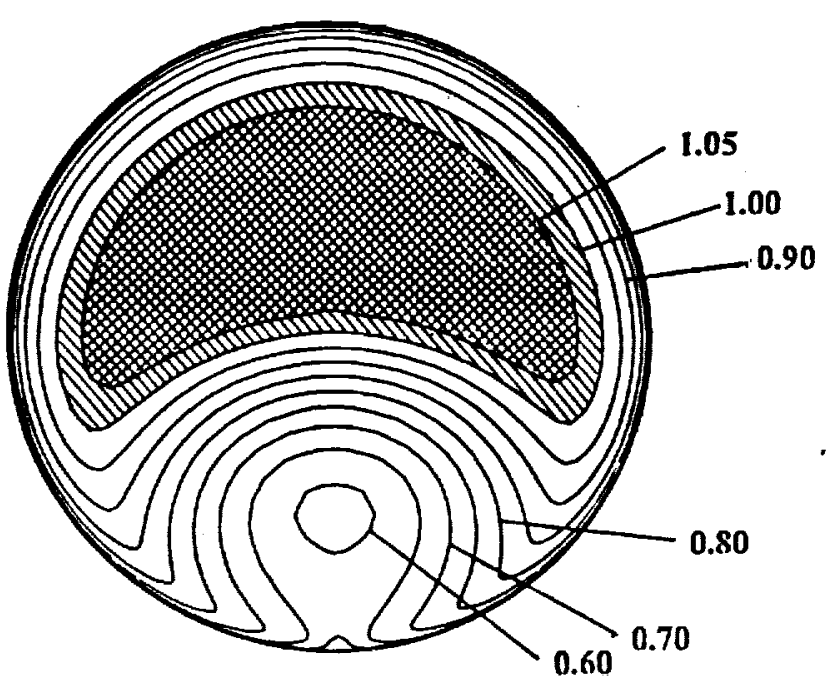

ANALYSIS, $y+=0.5$

Figure (3) - Total pressure coefficient contours without vortex generators, $\mathrm{X} / D_{i}=\mathbf{5 . 2}$.
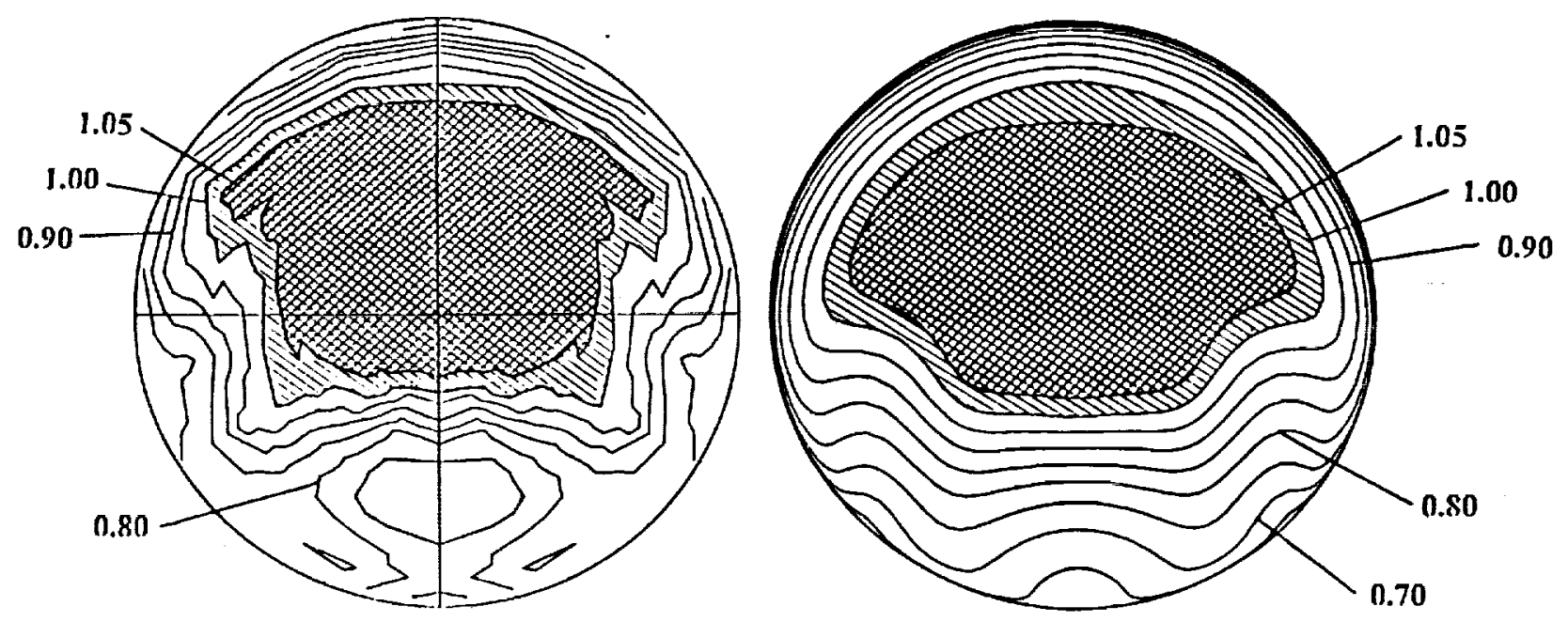

EXPERIMENTAL DATA

ANALYSIS, $y+=0.5$

Figure (4) - Total pressure coefficient contours with vortex generators, $\mathrm{X} / D_{i}=\mathbf{5 . 2}$. 


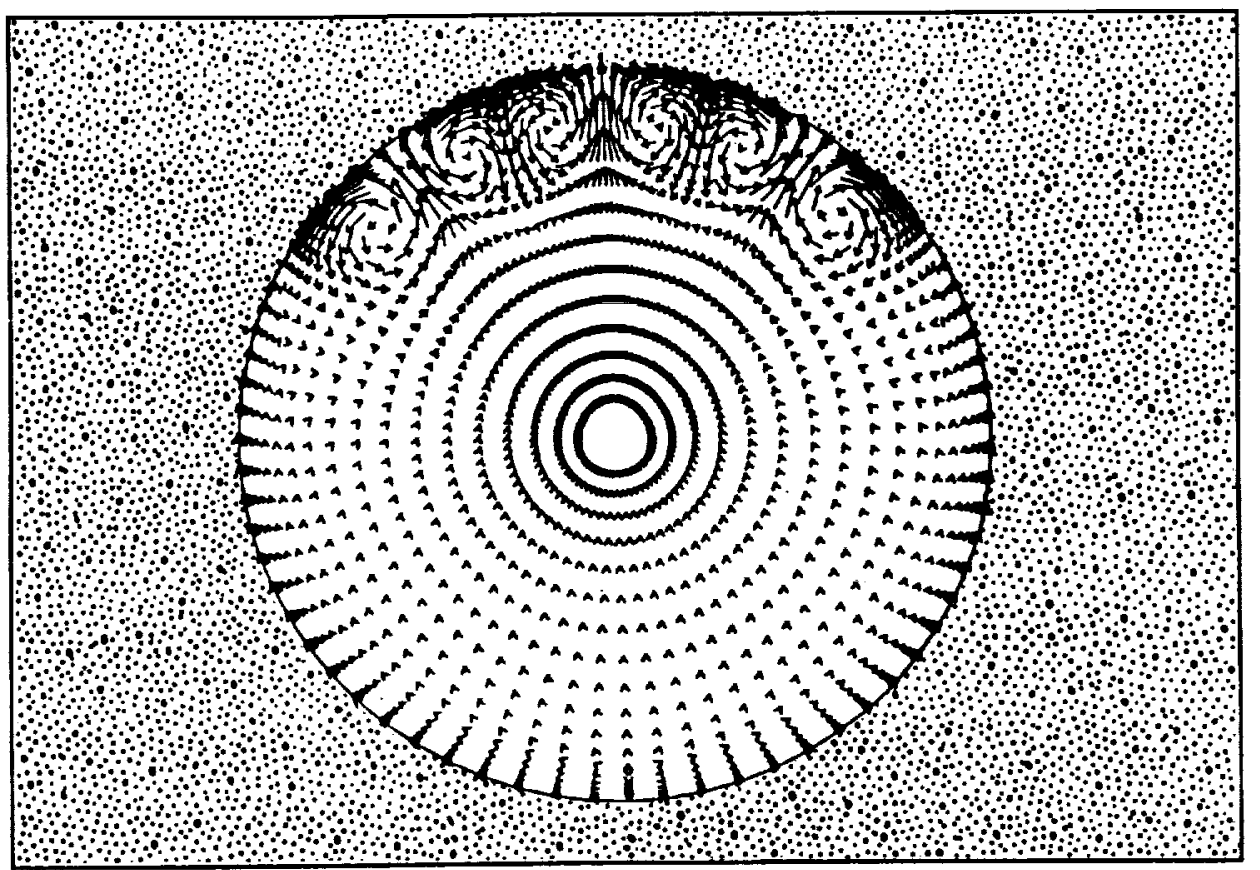

Figure (5) - Reduced Navier Stokes (RNS) solution showing secondary flow structure from vortex generator model, $X / D_{i}=0.18$.

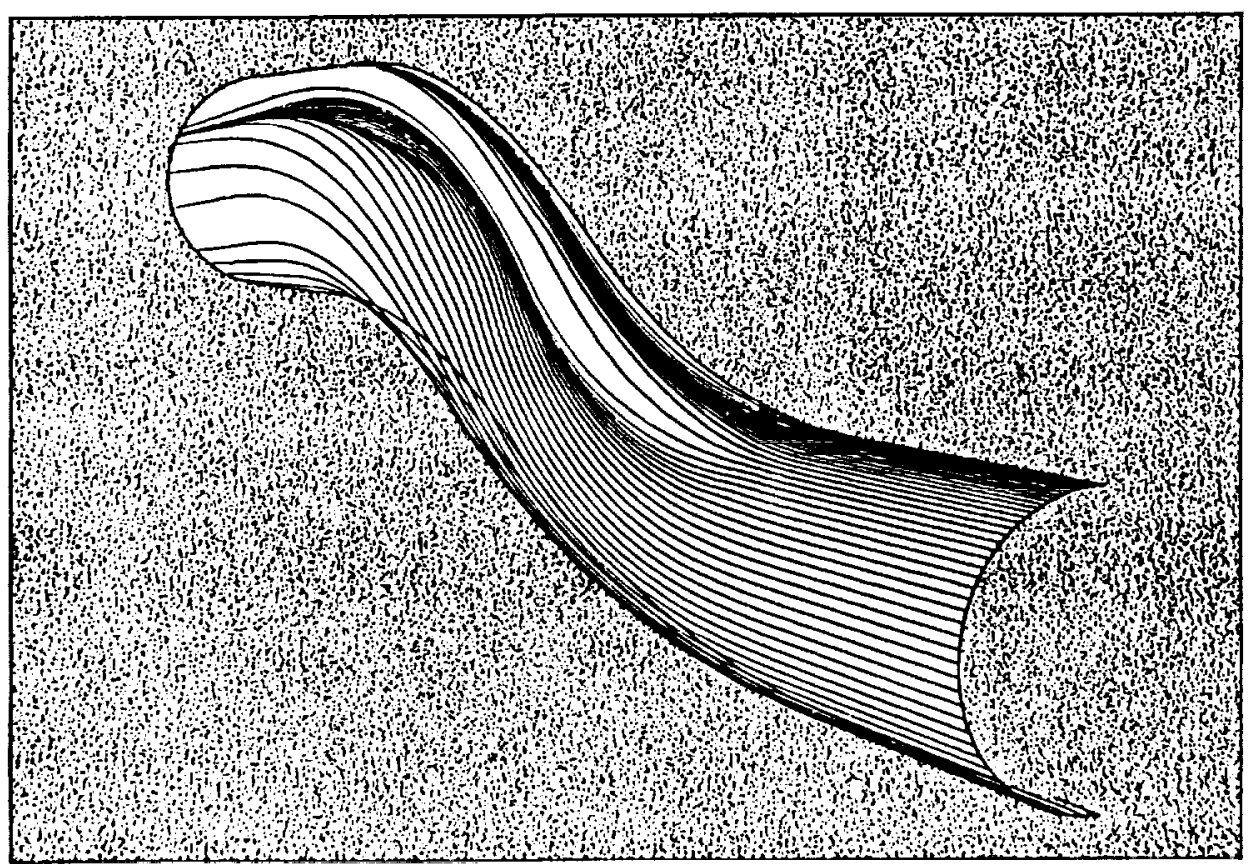

Figure (6) - Reduced Navier Stokes (RNS) solution showing limiting streamline signature of vortex generator region. 


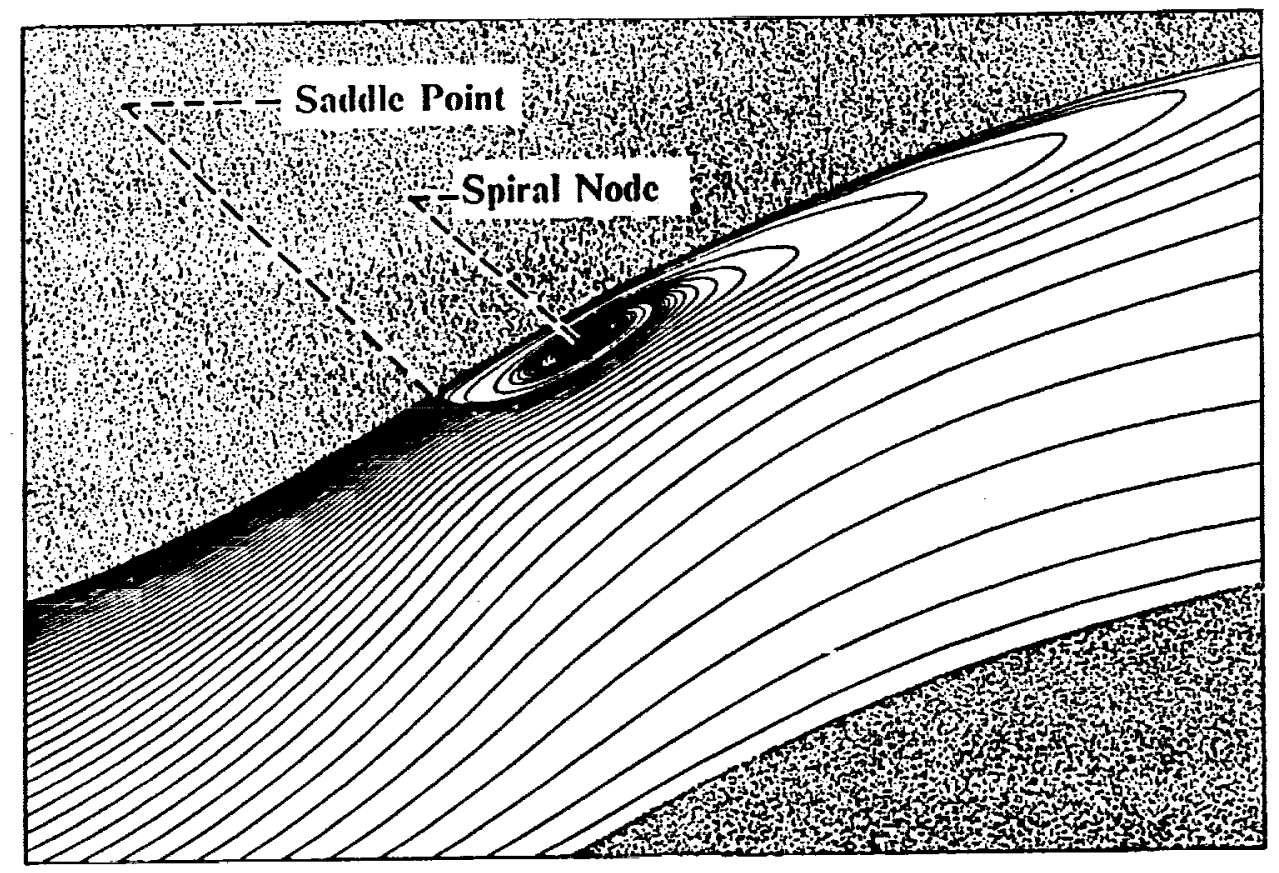

Figure (7) - Reduced Navier Stokes (RNS) solution showing limiting streamline signature of separation region within Univ. Tennessee diffusing $\mathbf{S}$-duct.

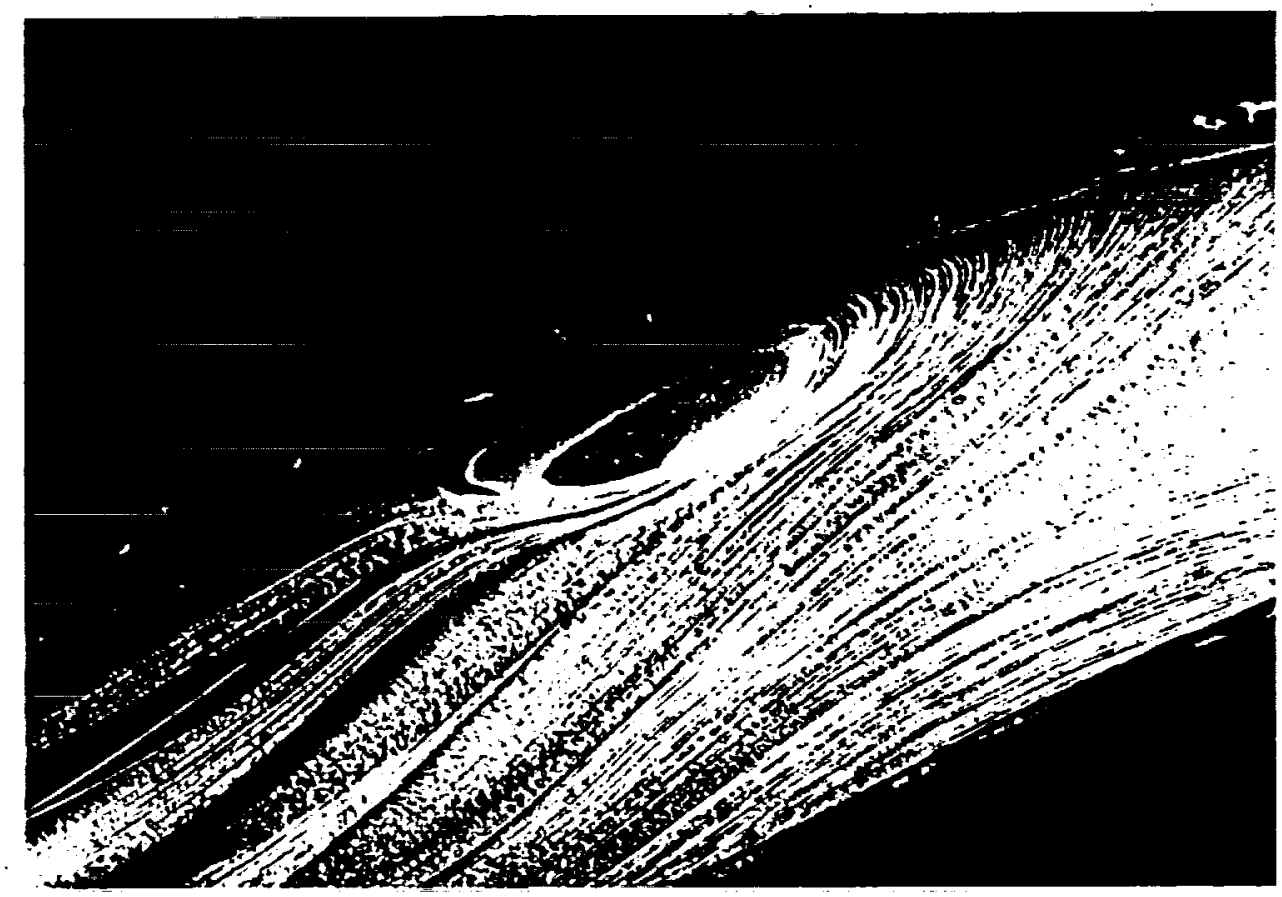

Figure (8) - Surface oil flow patterns showing separation region within Lniv. Tennessee diffusing S-duct. 


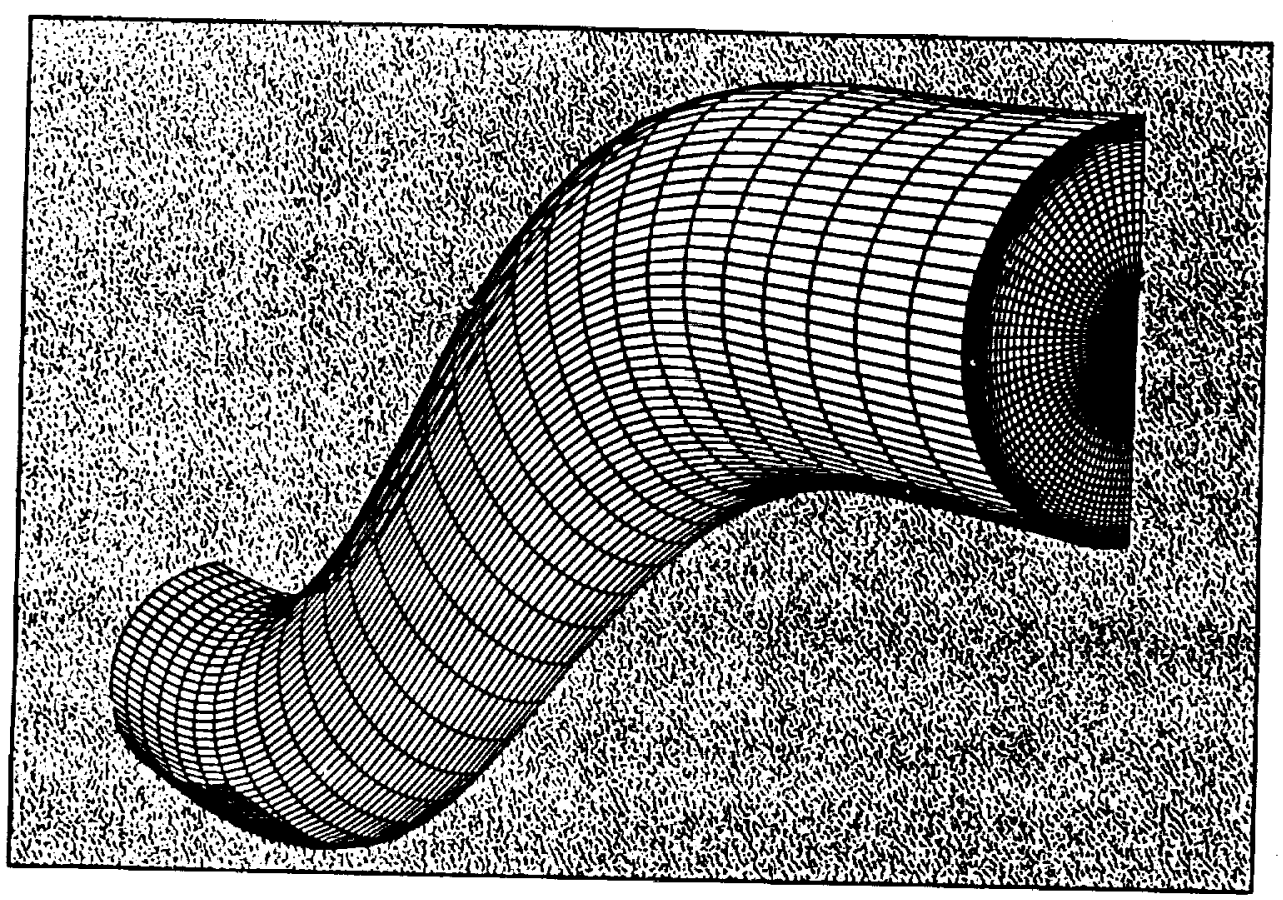

Figure (9) - Geometry definition for the 727/JT8D-100 center inlet.

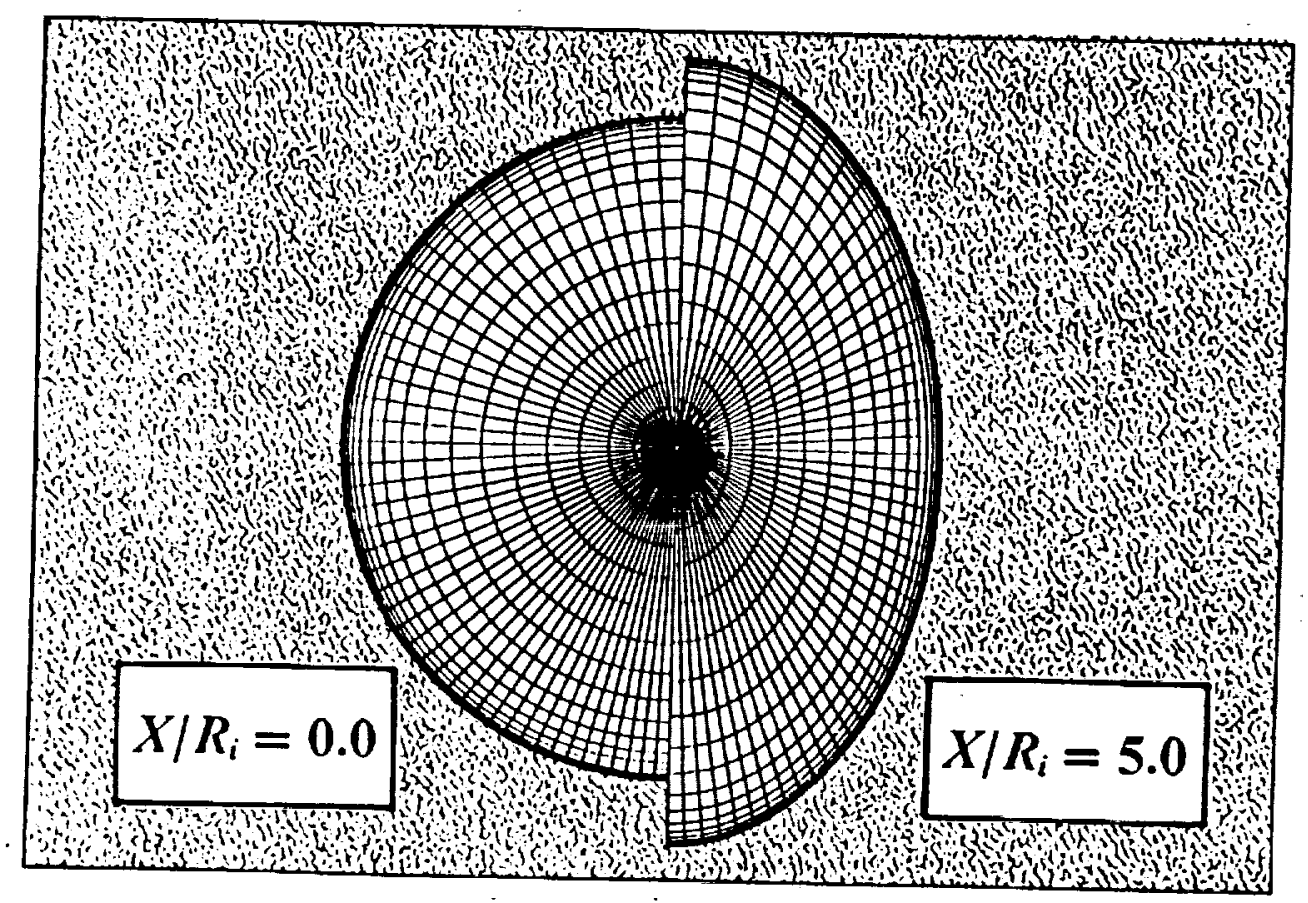

Figure (10) - Computation grid for the 727/JT8D-100 center inlet. 


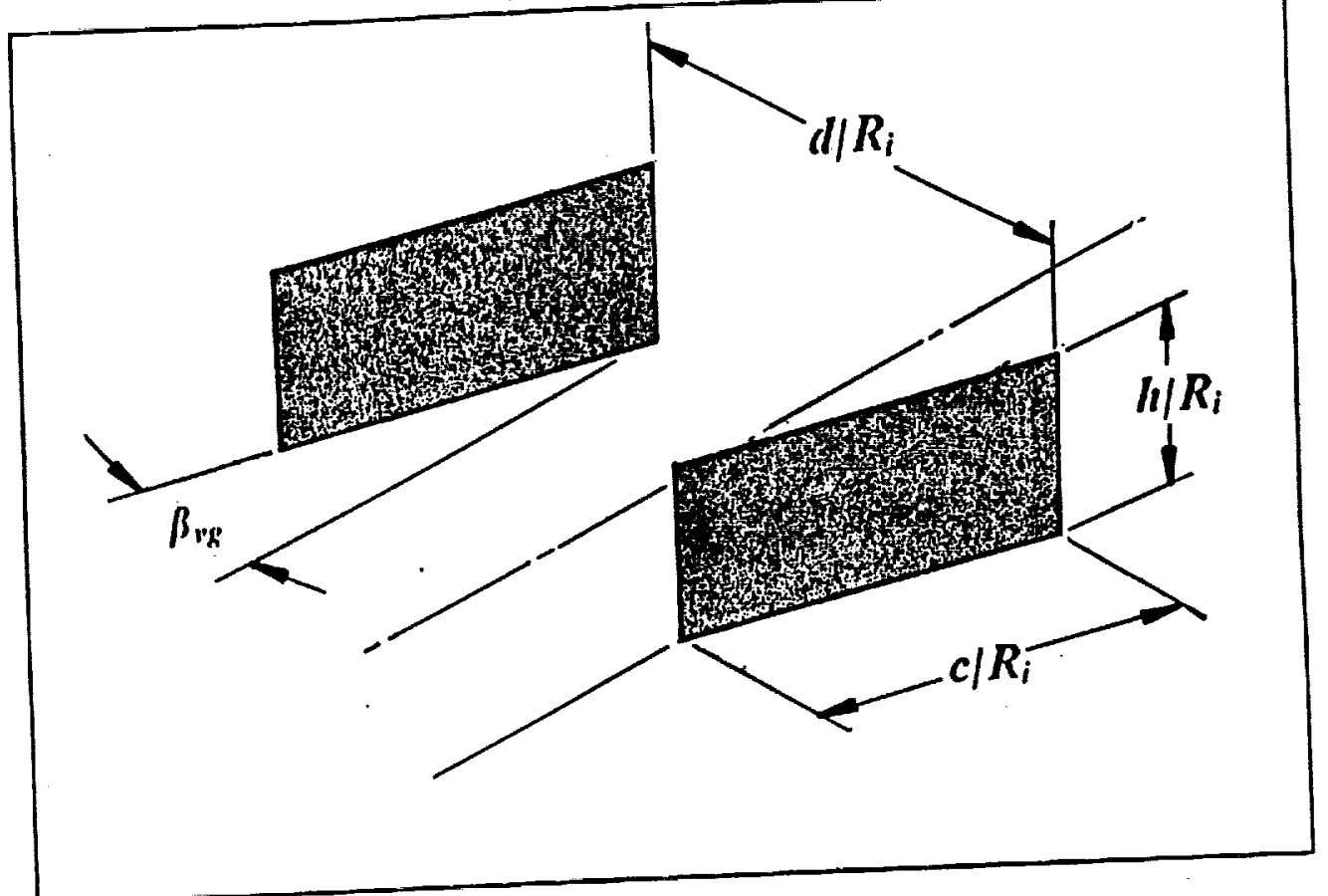

Figure (11) - Geometry definition of co-rotating vortex generators.

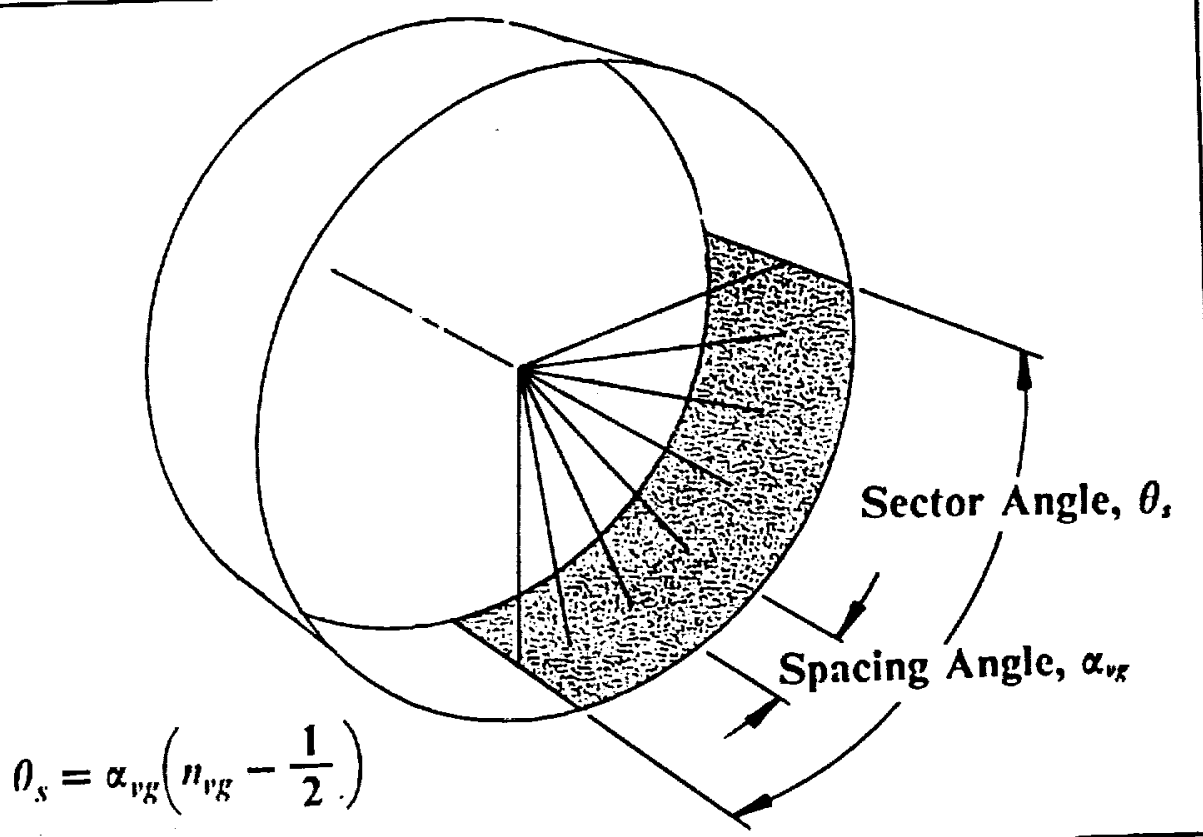

Figure (12) - Nomenclature used for vortex generator positioning. 


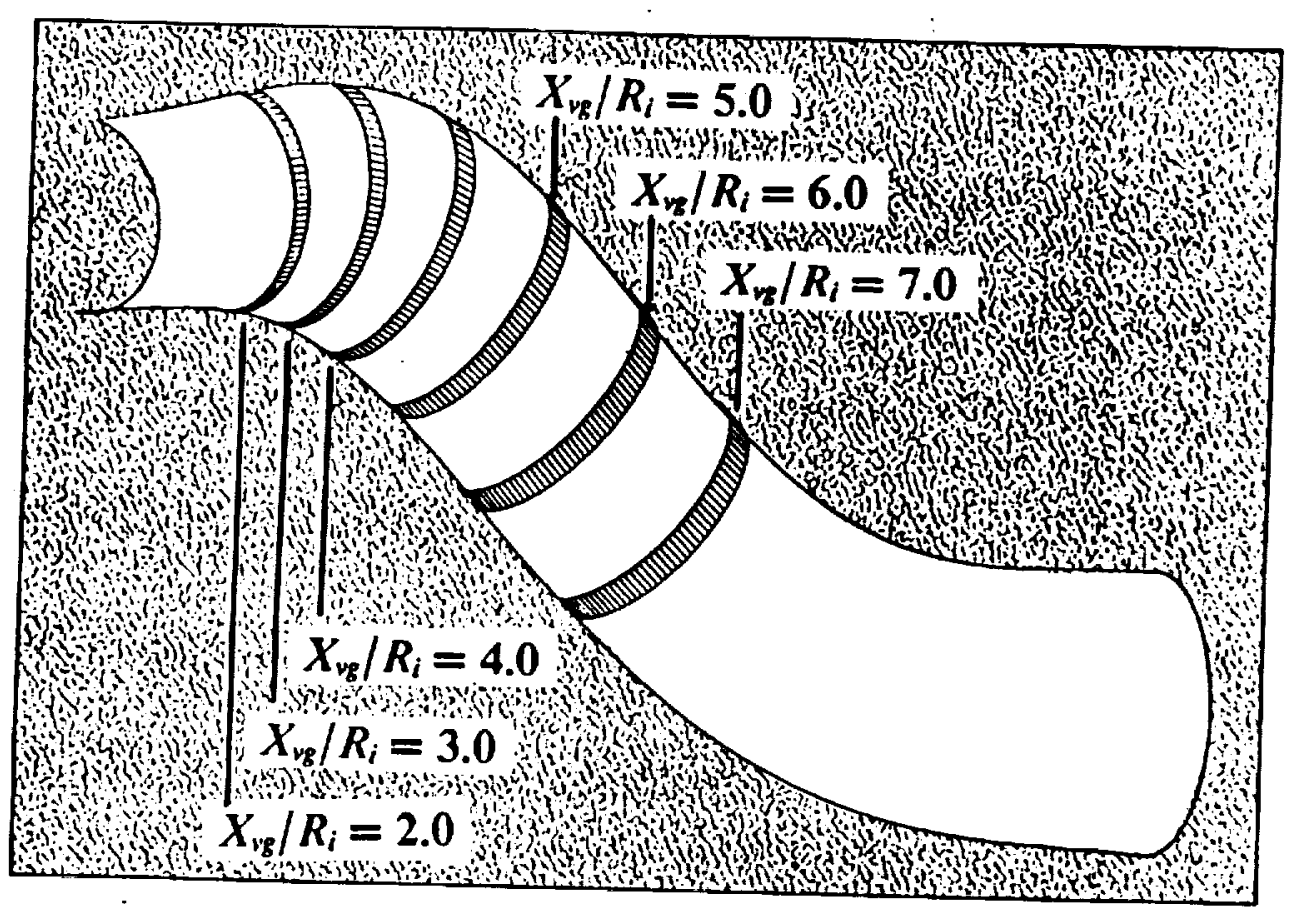

Figure (13) - Axial locations of the vortex generator sector regions.

\begin{tabular}{|c|c|c|c|c|c|c|c|}
\hline 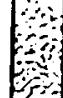 & Config. No. & $X_{\mathrm{rx}} / R_{i}$ & $n_{v g}$ & $\alpha_{i g}$ & 0 & Rejnolds No. & 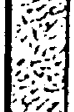 \\
\hline 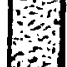 & 1 & 3.0 & II & 15.0 & 157.5 & $12.0 \times 10^{6}$ & \\
\hline 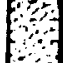 & 2 & 3.0 & 9 & 15.0 & 127.5 & $12.0 \times 10^{6}$ & \\
\hline 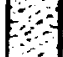 & 3 & 3.0 & 7 & 15.0 & 97.5 & $12.0 . \times 10^{6}$ & 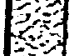 \\
\hline 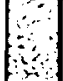 & 4 & 3.0 & 5 & 15.0 & 67.5 & $12.0 \times 10^{6}$ & \\
\hline 2 & 5 & 2.0 & 9 & 15.0 & 127.5 & $12.0 . \times 10^{6}$ & \\
\hline$\theta$ & 6 & 3.0 & 9 & 15.0 & 127.5 & $12.0 . \times 10^{6}$ & 0 \\
\hline 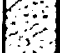 & 7 & 4.0 & 9 & 15.0 & 127.5 & $12.0 \times 10^{6}$ & 3 \\
\hline$\therefore$ & 8 & 5.0 & 9 & 15.0 & 127.5 & $12.0 \times 10^{6}$ & 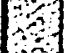 \\
\hline 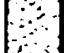 & 9 & 6.0 & 9 & 15.0 & 127.5 & $12.0 \times 10^{6}$ & 8 \\
\hline 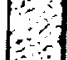 & 10 & 7.0 & 9 & 15.0 & 127.5 & $12.0 \times 10^{6}$ & \\
\hline
\end{tabular}

Table I - 727/JT8D- 100 center inlet duct vortex generator configurations. 


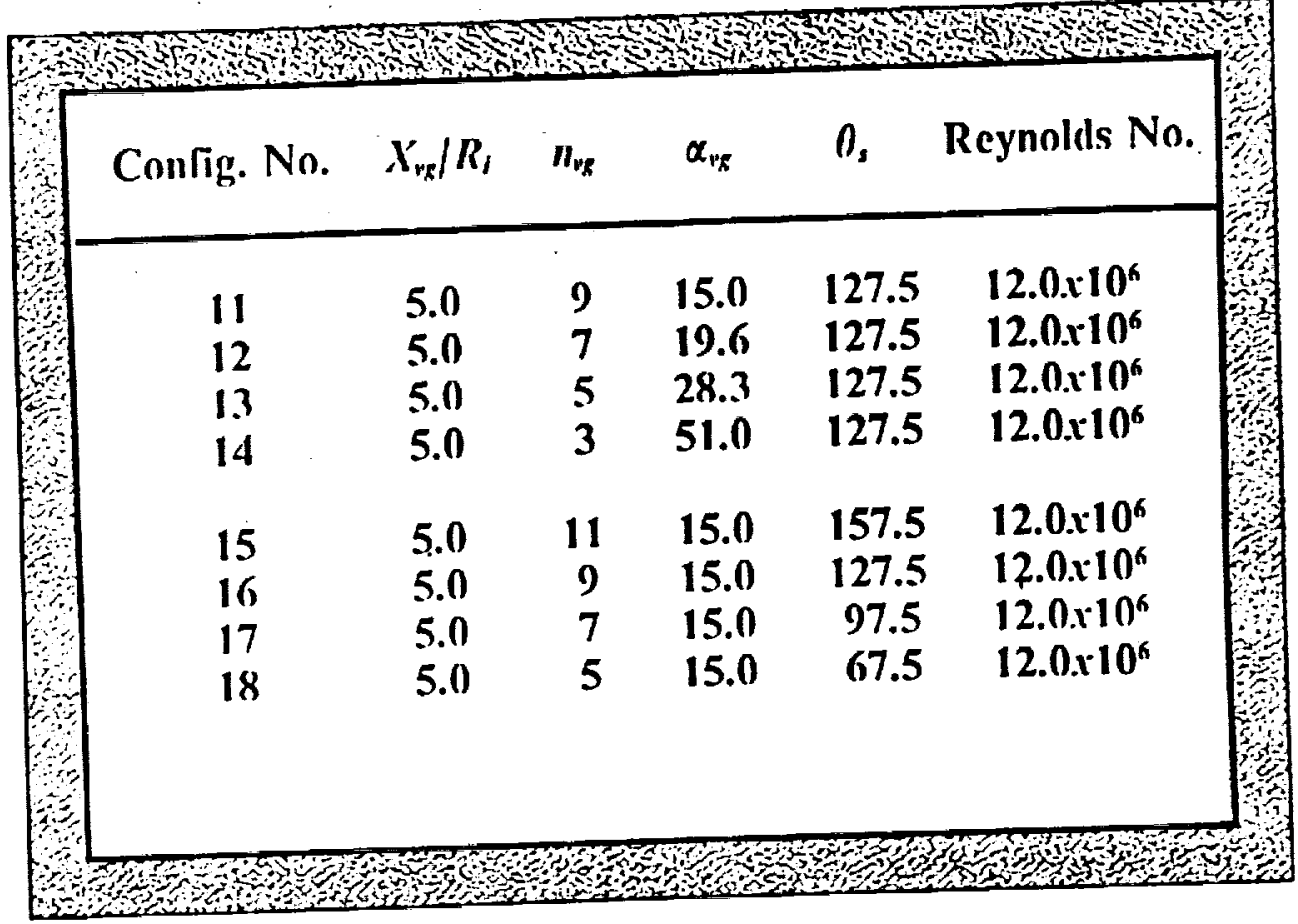

Table II - 727/JT8D-100 center inlet duct vortex generator configurations.

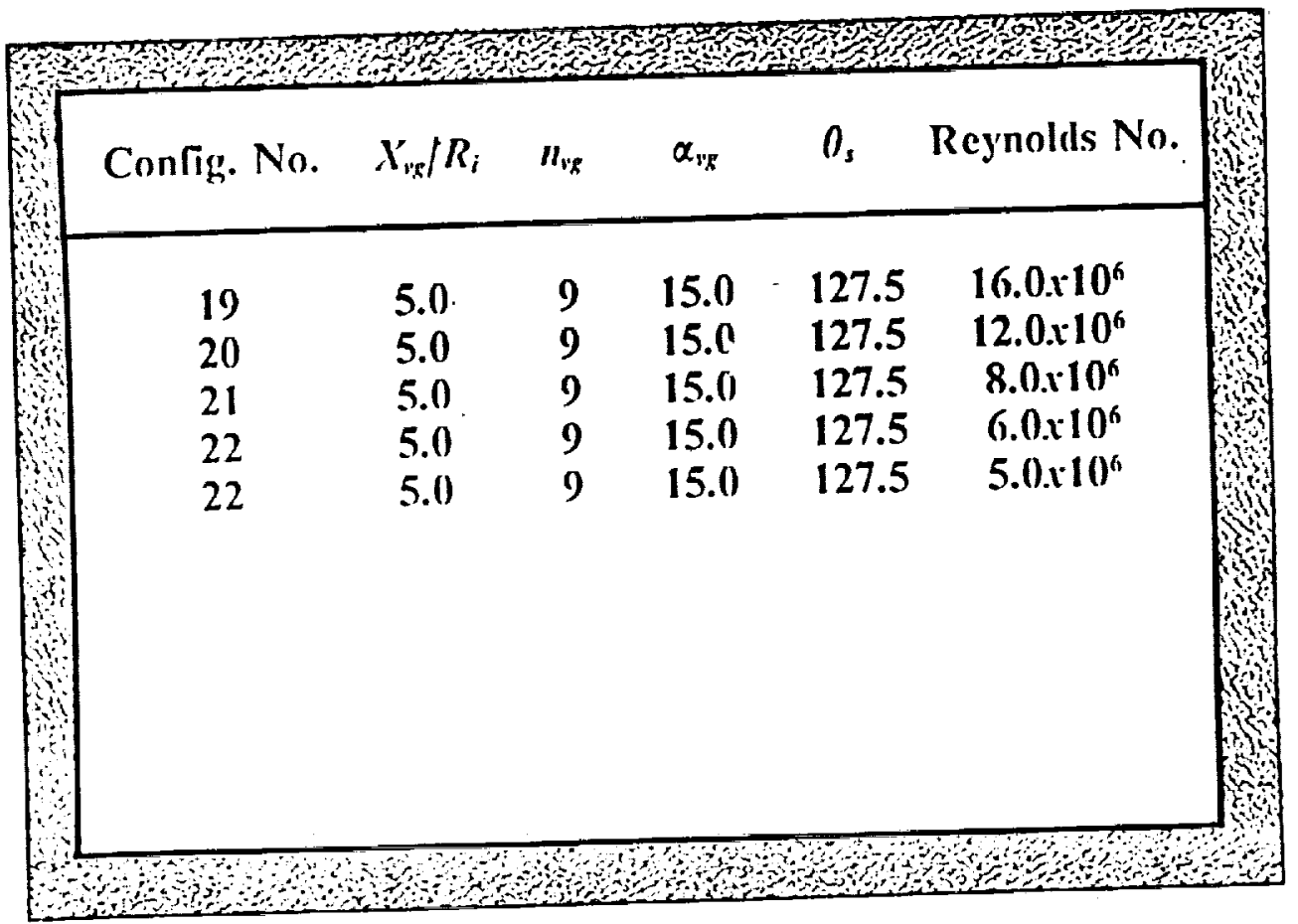

Table III - 727/JT8D-100 center inlet duct vortex generator configurations. 


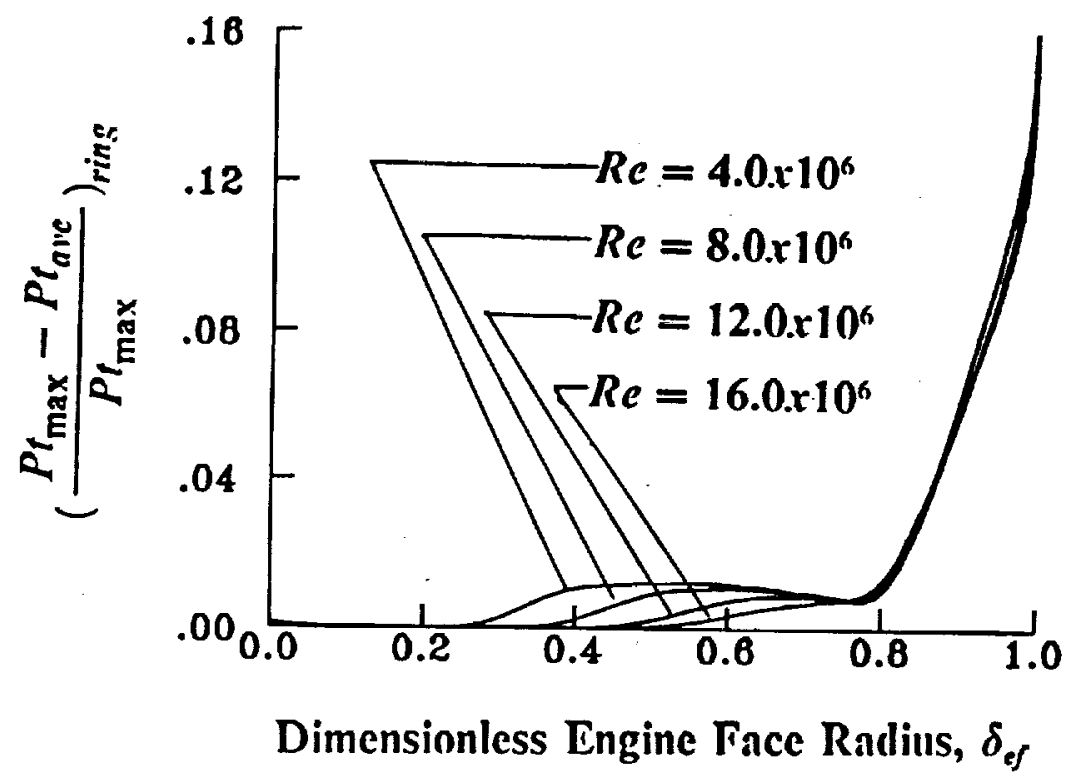

Figure (14) - Effect of Reynolds number on radial pressure ring distortion without vortex flow control.

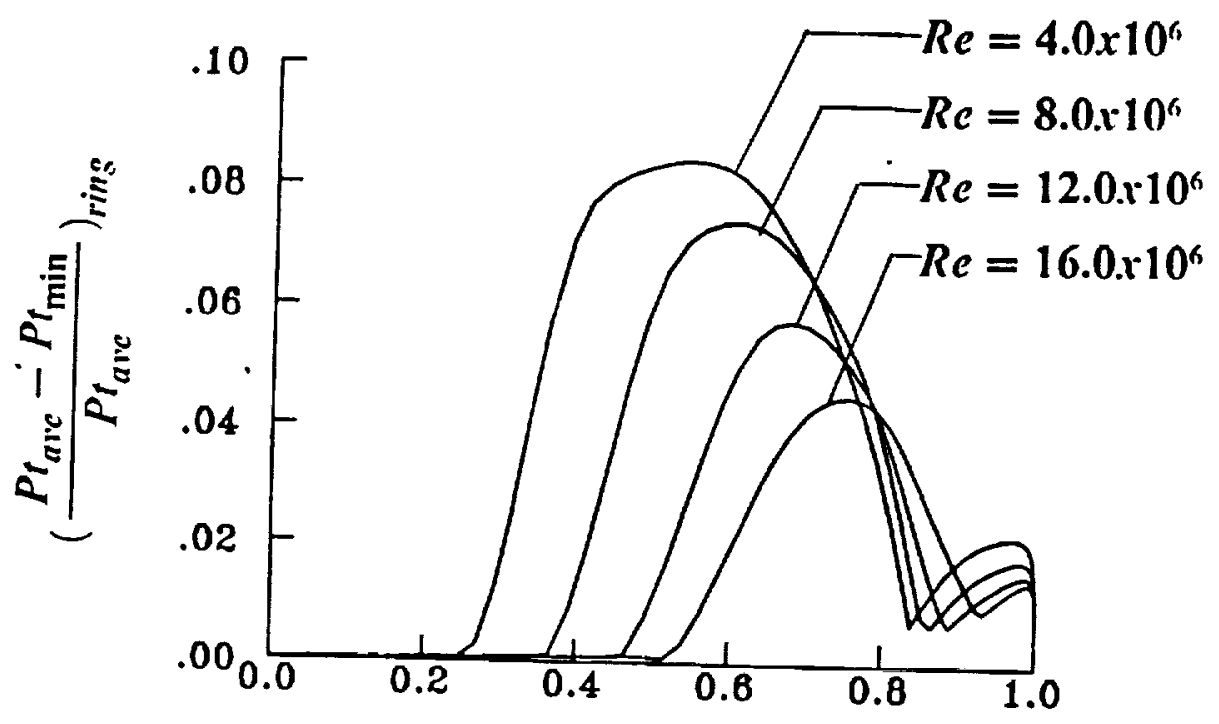

Dimensionless Engine Face Radius, $\delta_{c f}$

Figure (15) - Effect of Reynolds number on the $60^{\circ}$-sector circumferential pressure ring distortion without vortex flow control. 


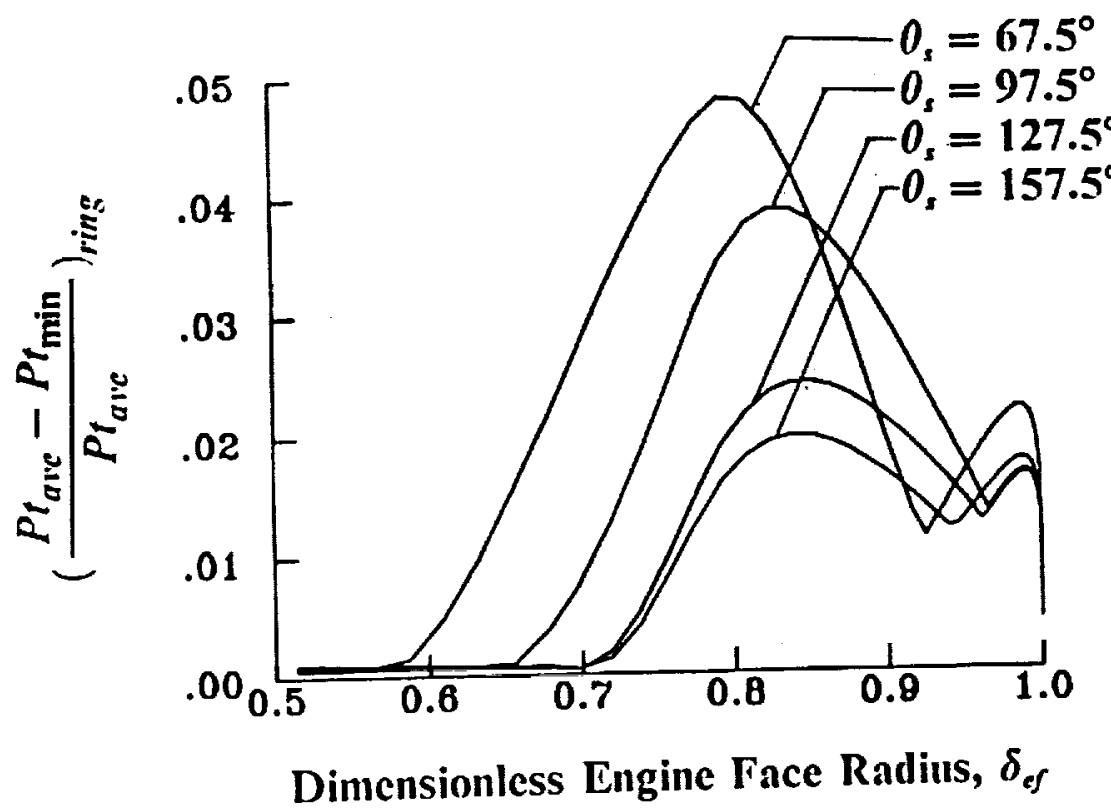
Figure (16) - Effect of vortex control sector angle $\left(\theta_{s}\right)$ on the $60^{\circ}$-sector
circunferential pressure ring distortion at $X_{y_{z}} / R_{i}=3.0$.

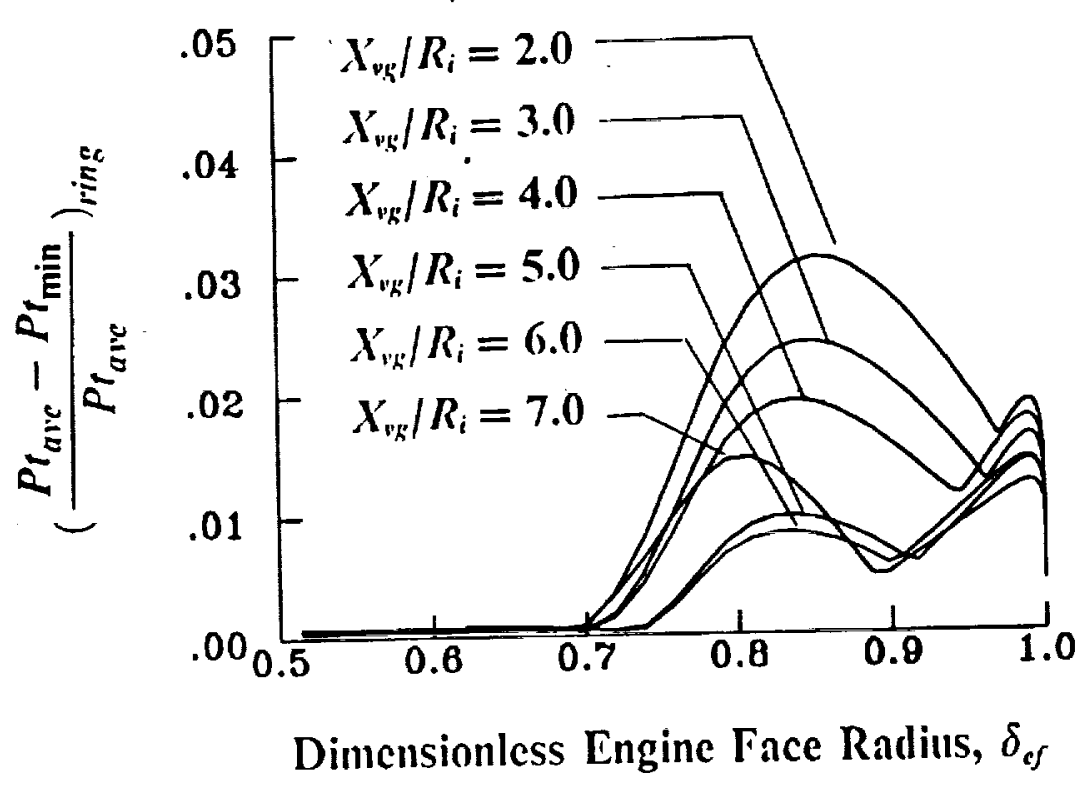

Figure (17) - Effect of vortex control sector location $\left(X_{r^{\prime}} / R_{i}\right)$ on the $60^{\circ}$-sector circumferential pressure ring distortion. 


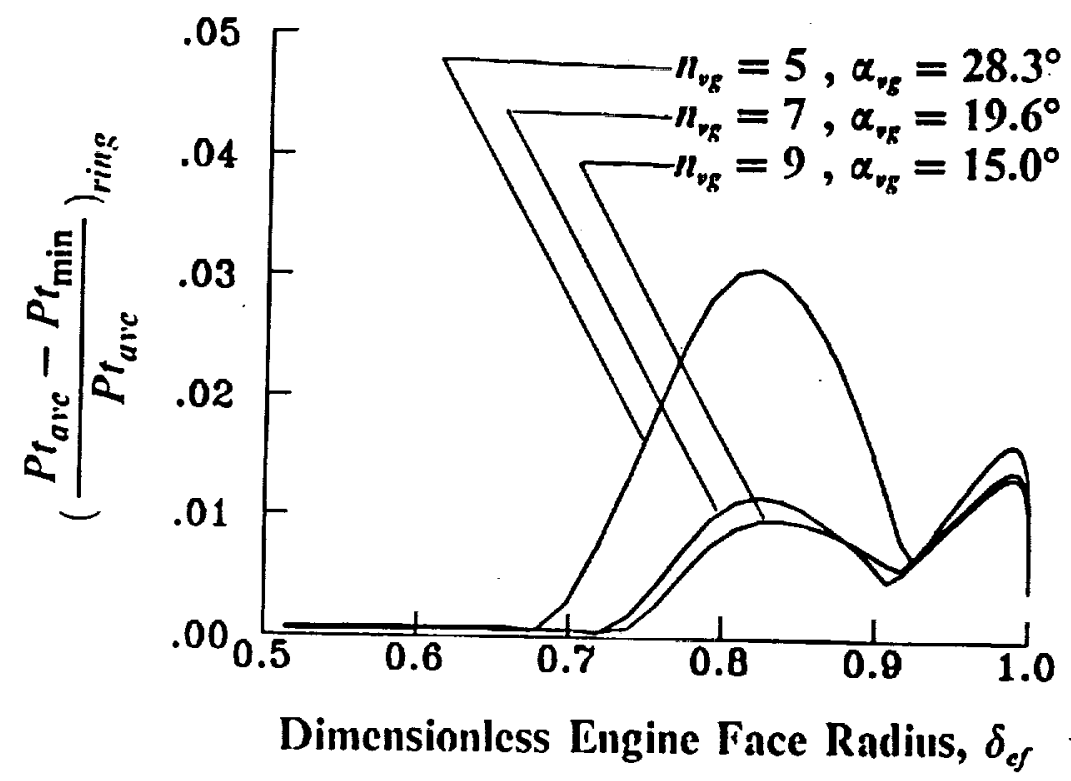

Figure (18) - Effect of vortex control spacing angle $\left(\alpha_{v z}\right)$ on the $60^{\circ}$-sector circumferential ring distortion at $X_{v i} / R_{i}=5.0$.

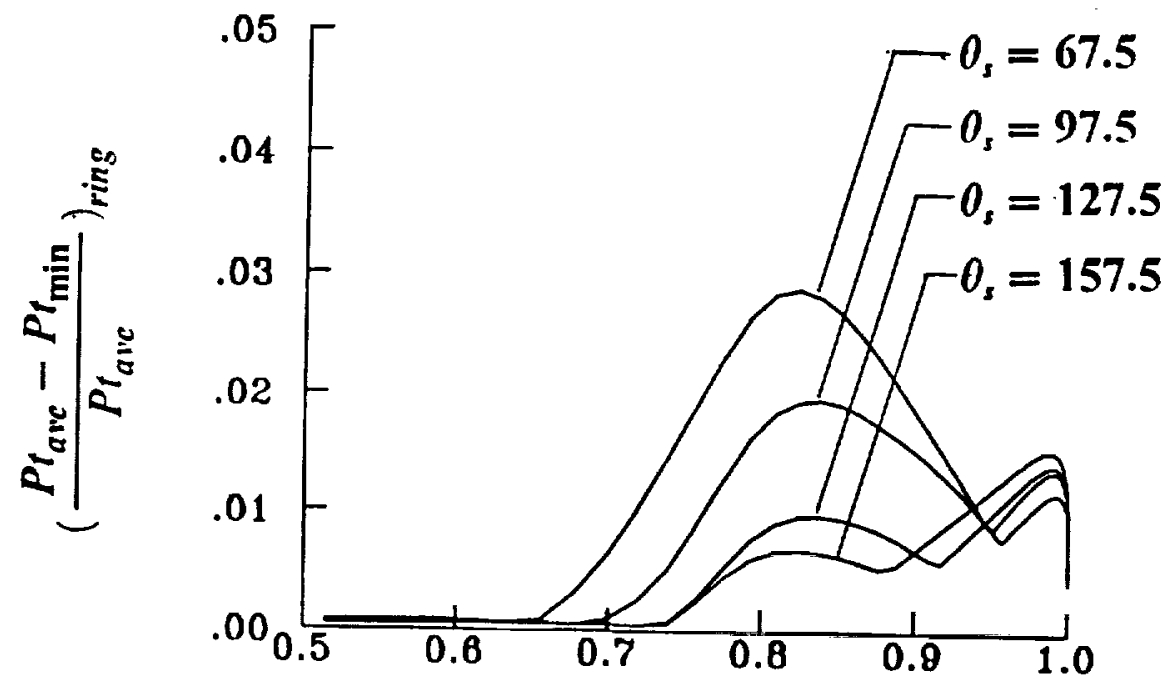

Dimensionless Engine Face Radius, $\delta_{\text {ef }}$

Figure (19) - Effect of vortex control sector angle $\left(\theta_{s}\right)$ on the $60^{\circ}$-sector circumferential pressure ring distortion at $X_{r_{s}} / R_{i}=5.0$. 


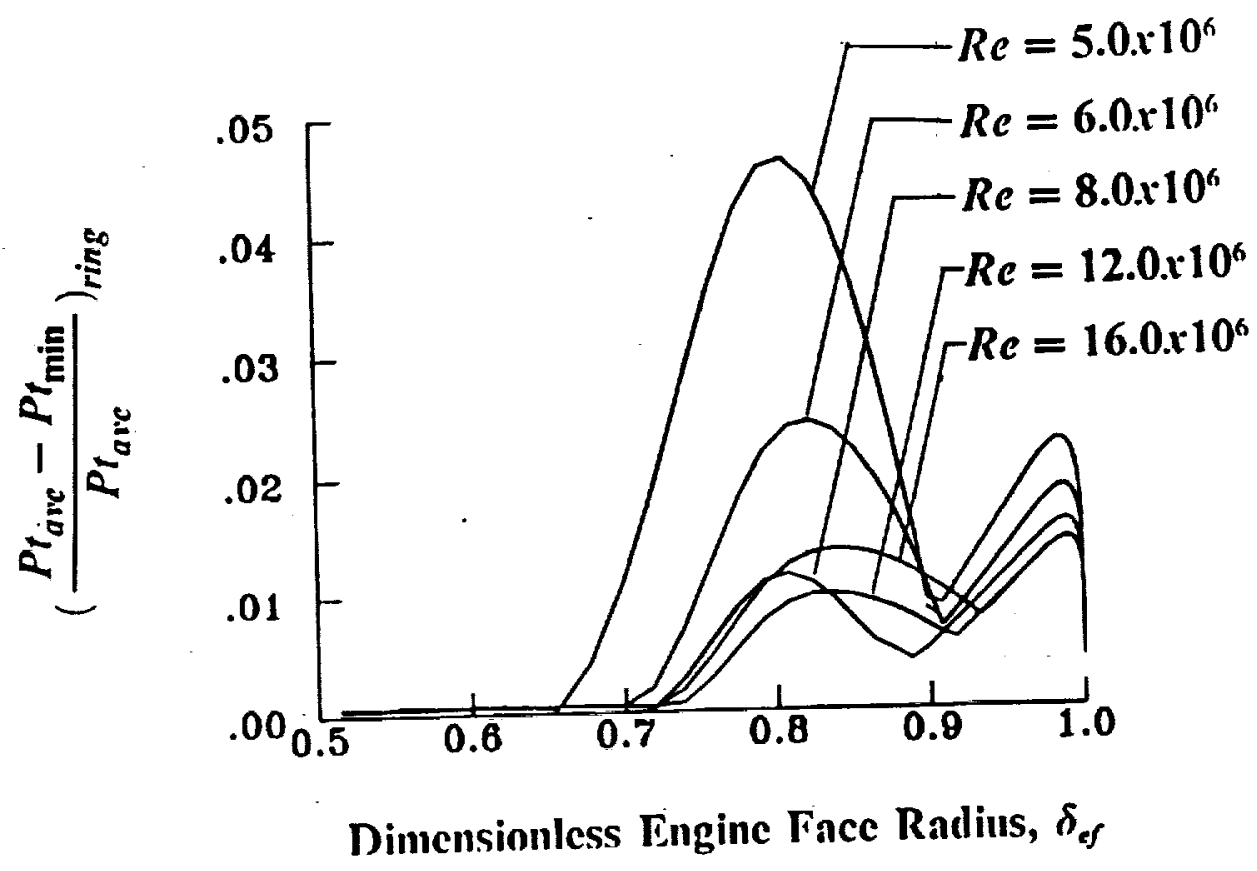

Figure (20) - Effect of Reynolds number on the $60^{\circ}$-sector circumferential pressure ring distortion at $X_{v s} / R_{i}=\mathbf{5 . 0}$.

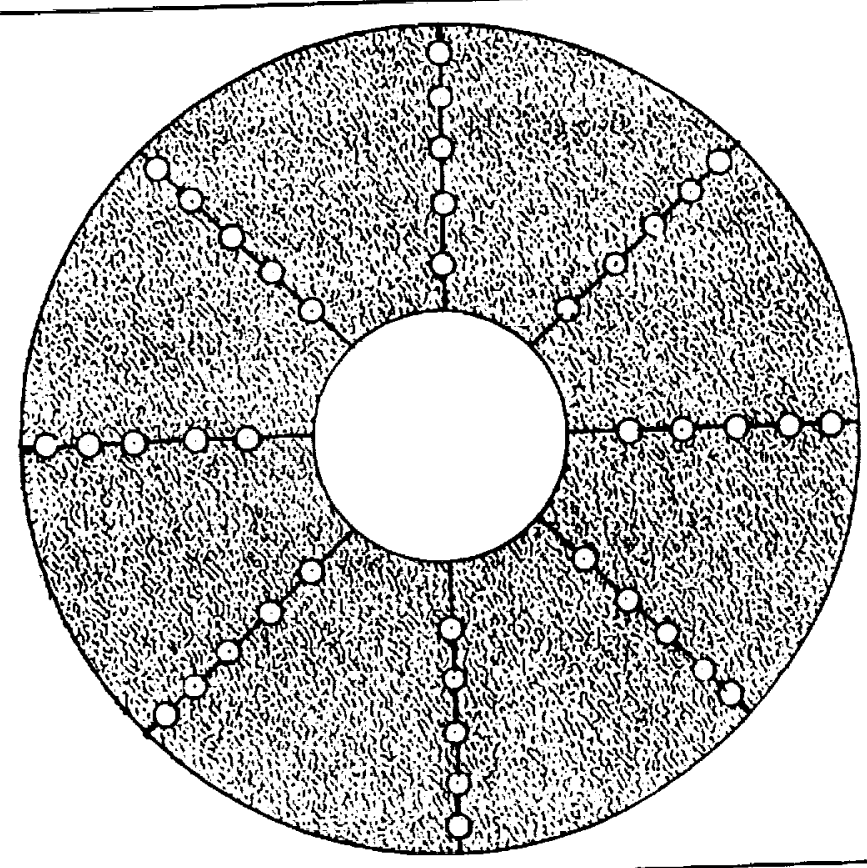

Figure (21) - Standard 40-probe rake geometry and probe locations. 


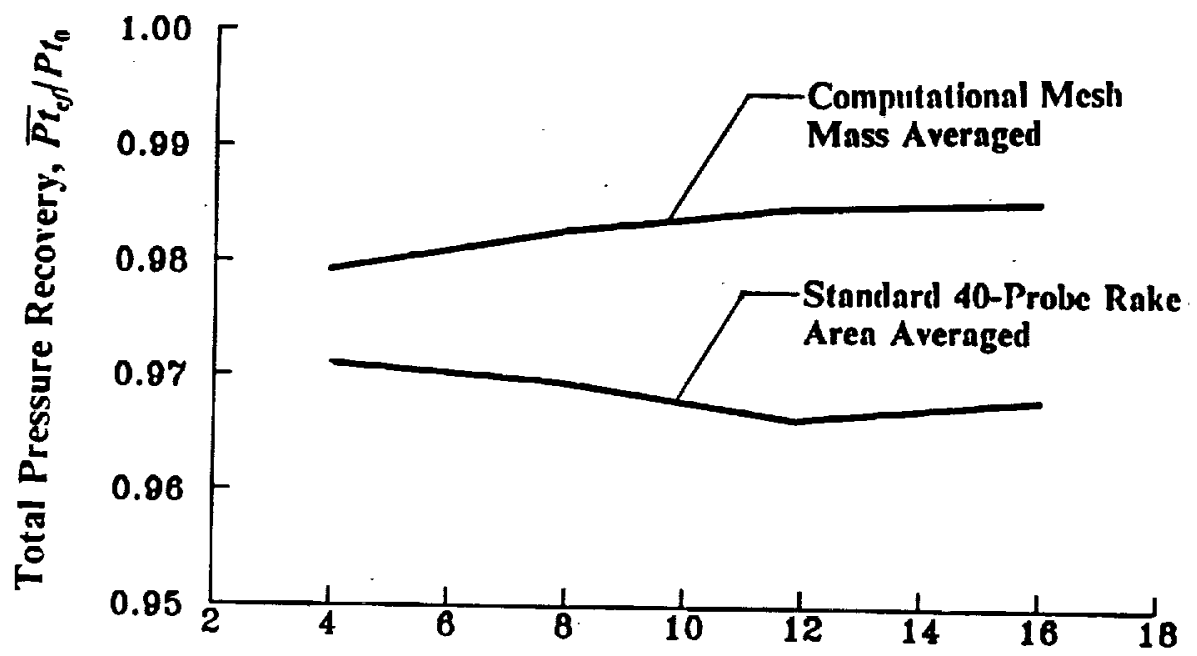

Reynolds Number, Re x 10-6

Figure (22) - Effect of Reynolds number on the engine face total pressure recovery $\left(\overline{P t_{e}} / P t_{0}\right)$ without vortex flow control.

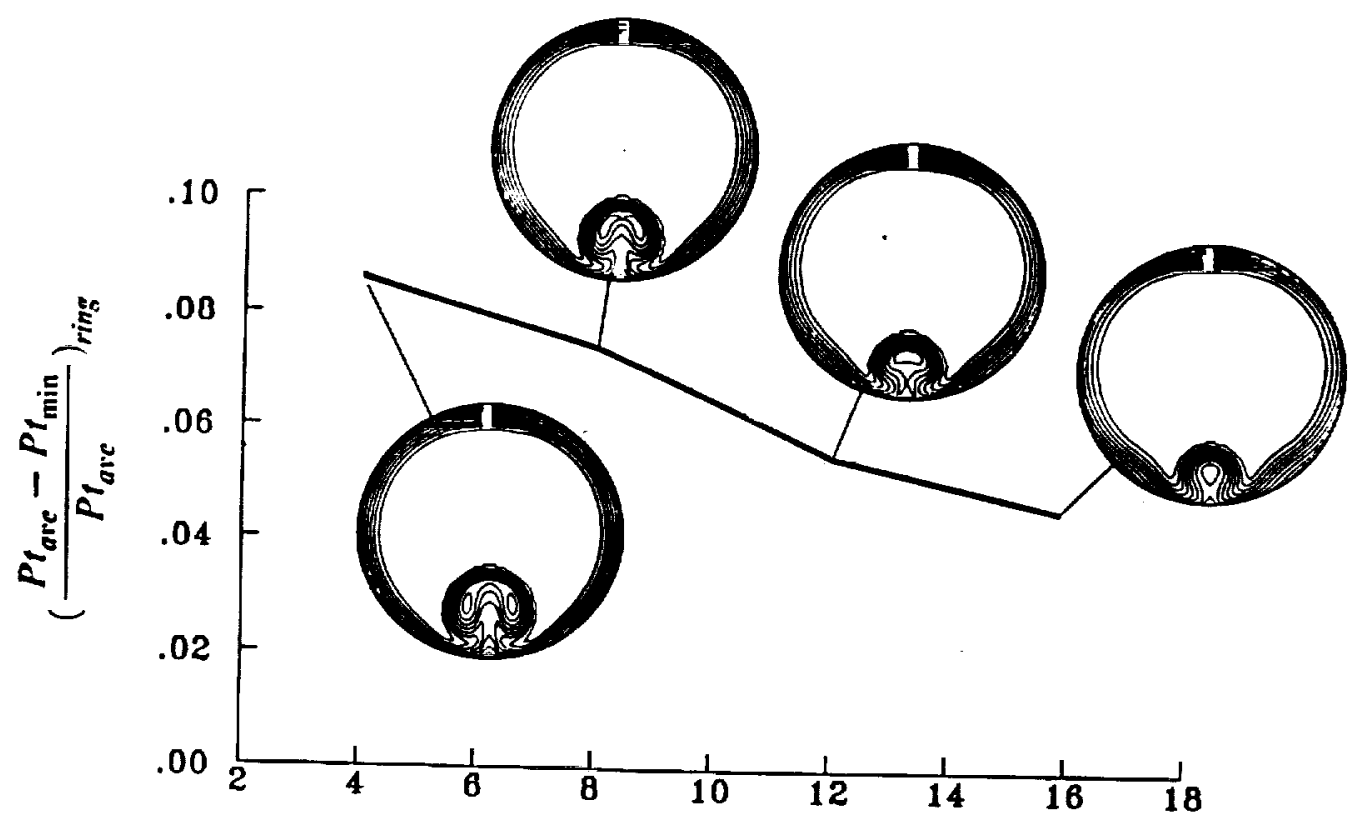

Reynolis Number, Re $\times 10^{-6}$

Figure (23) - Effect of Reynolds number on the maximum $60^{\circ}$-sector circumferential pressure ring distortion without vortex flow control. 


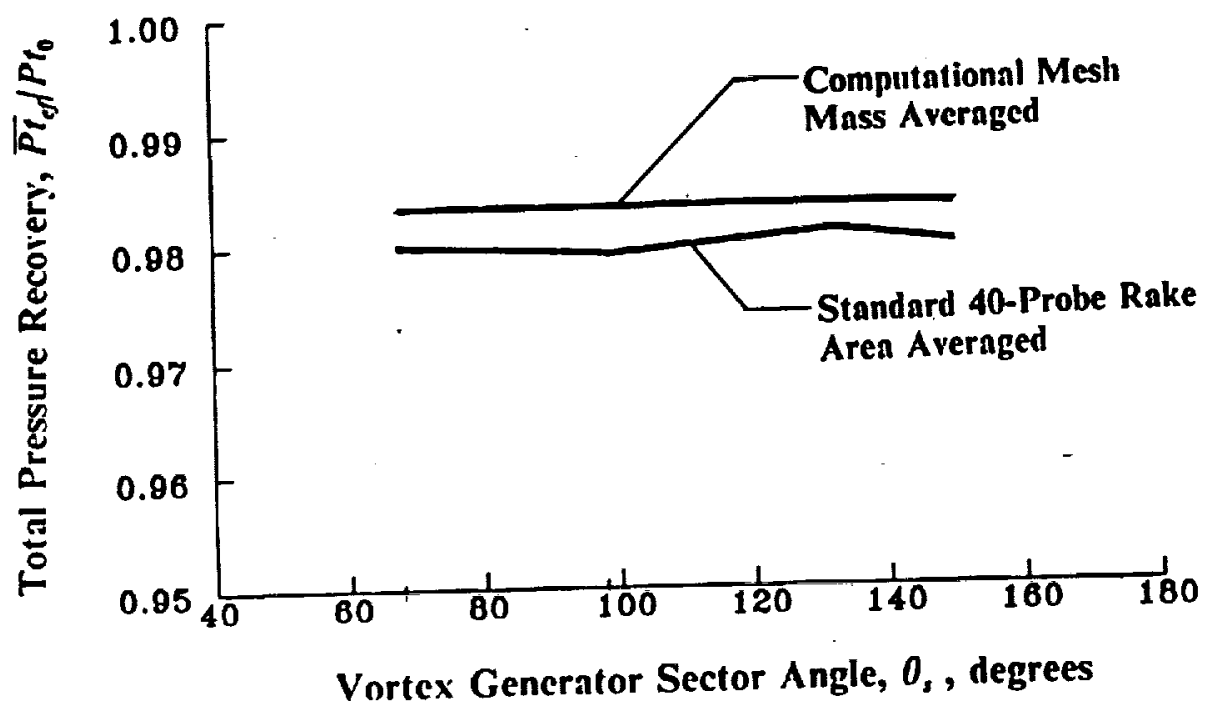

Figure (24) - Effect of vortex generator sector angle $\left(\theta_{3}\right)$ on the engine face total pressure recovery $\left(\bar{P}_{t_{f}} f P t_{0}\right)$ at $X_{v_{z}} / D_{i}=3.0$.

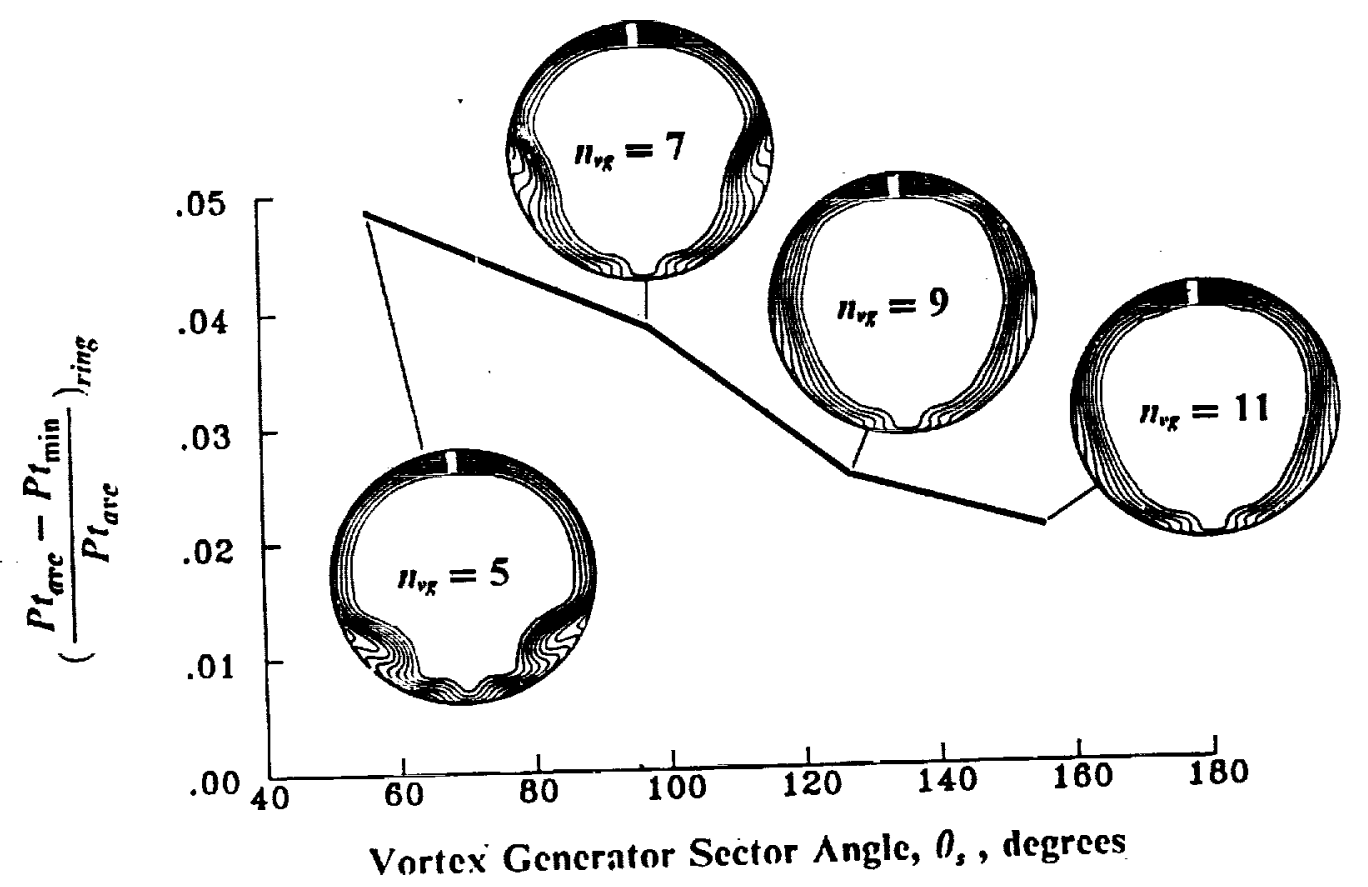

Figure (25) - Effect of vortex generator sector angle $\left(\theta_{s}\right)$ on the maximum
$60^{\circ}$-sector circumferential pressure ring distortion at $X_{v_{g}} / R_{i}=3.0$. 


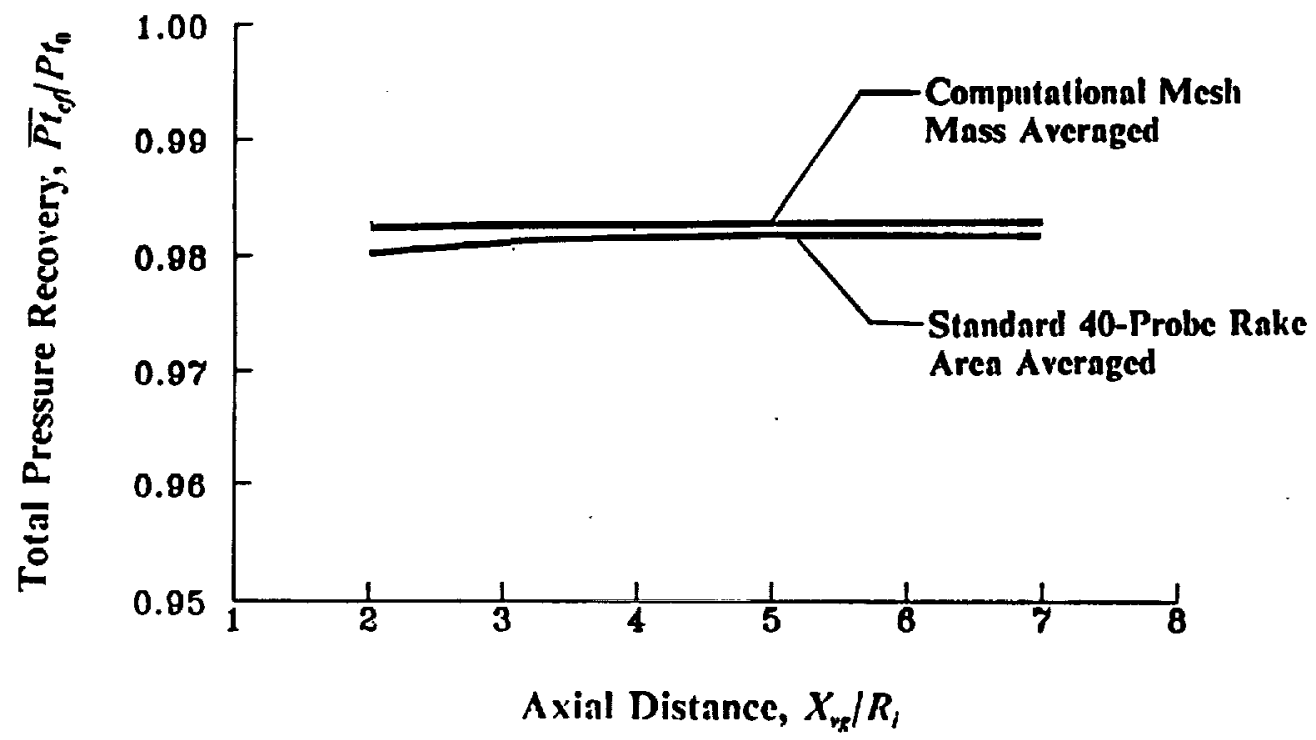

Figure (26) - Effect of vortex generator sector location $\left(X_{v g} / R_{i}\right)$ on the engine face total pressure recovery $\left(\overline{P t_{e}} / P t_{0}\right)$.

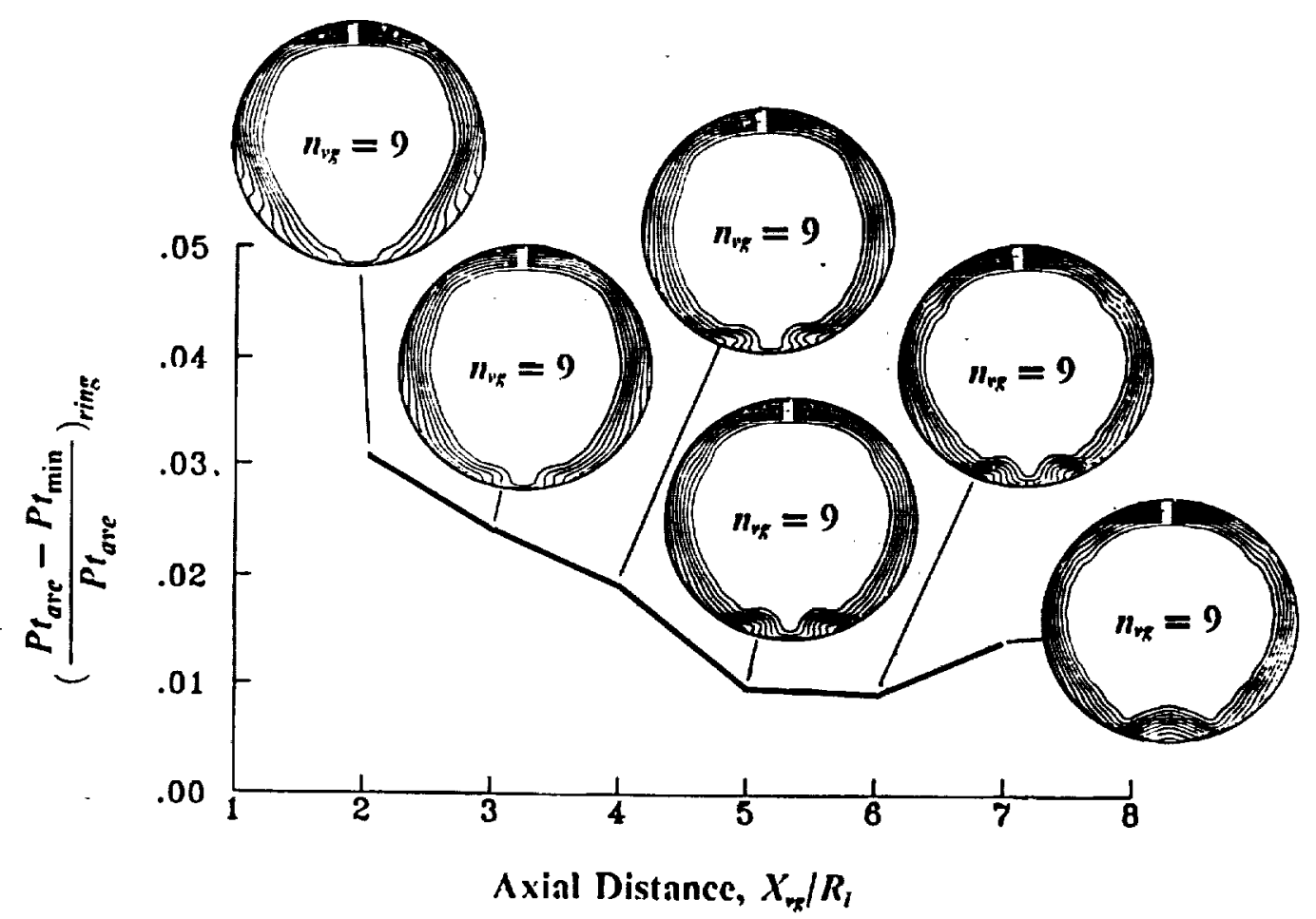

Figure (27) - Effect of vortex generator sector location $\left(X_{v g} / R_{i}\right)$ on the maximum $60^{\circ}$-sector circumferential pressure ring distortion. 


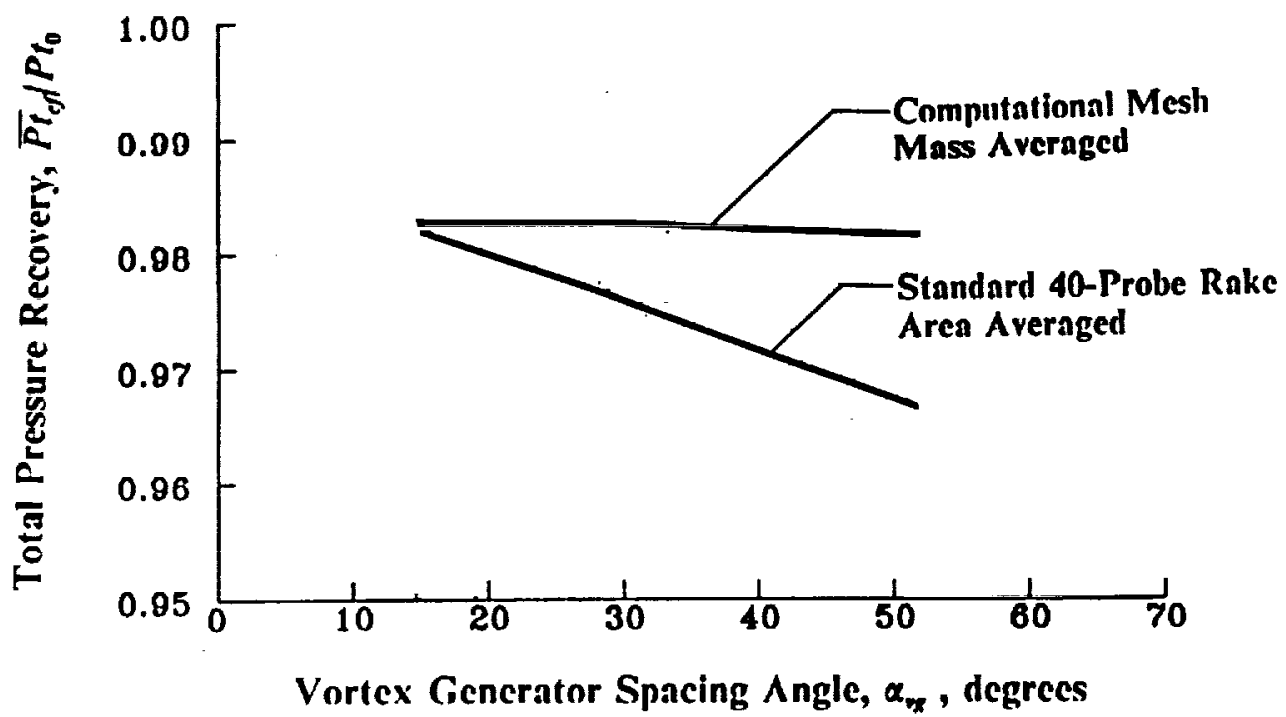

Figure (28) - Effect of vortex generator spacing angle $\left(\alpha_{v z}\right)$ on the engine face total pressure recovery $\left.\left(\overline{P t}_{f f}\right) \boldsymbol{P t}_{0}\right)$.

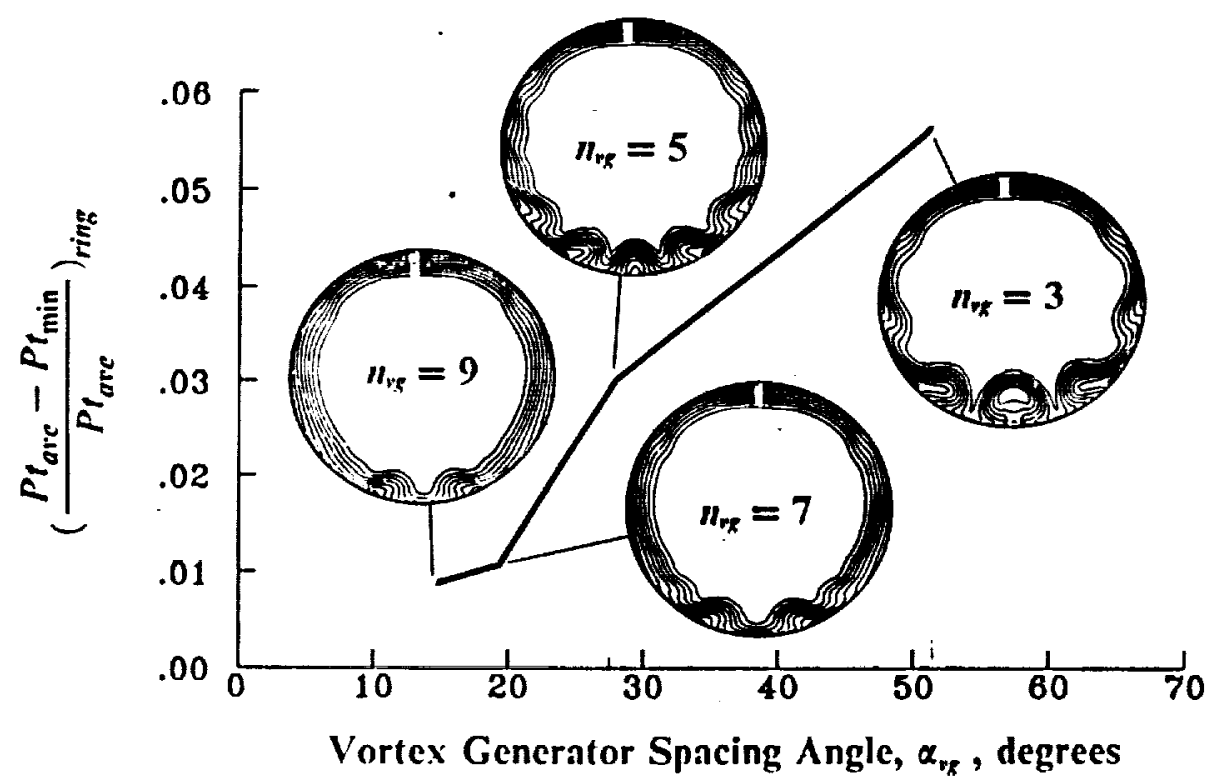

Figure (29) - Effect of vortex generator spacing angle $\left(x_{y g}\right)$ on the maximum $60^{\circ}$-sector circumferential pressure ring distortion. 


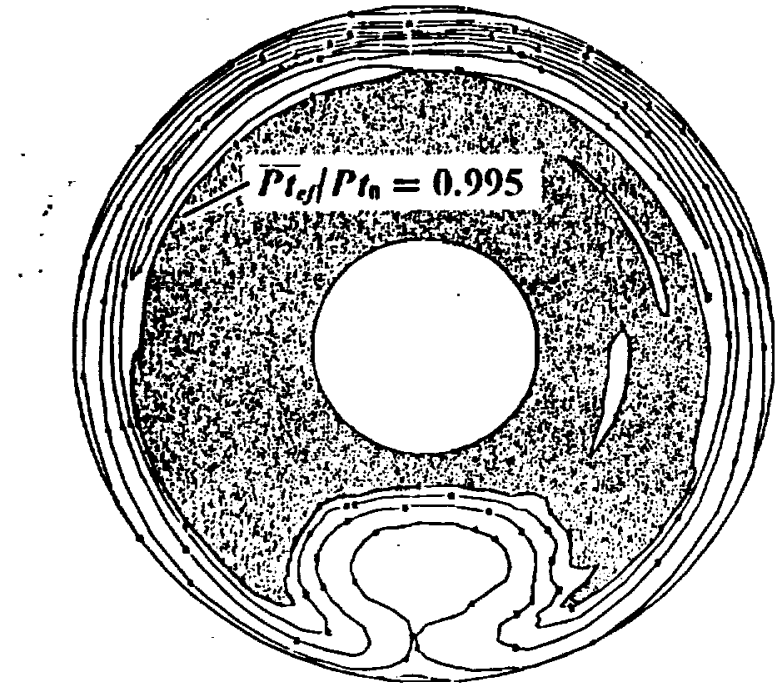

EXPERIMENTAL DATA

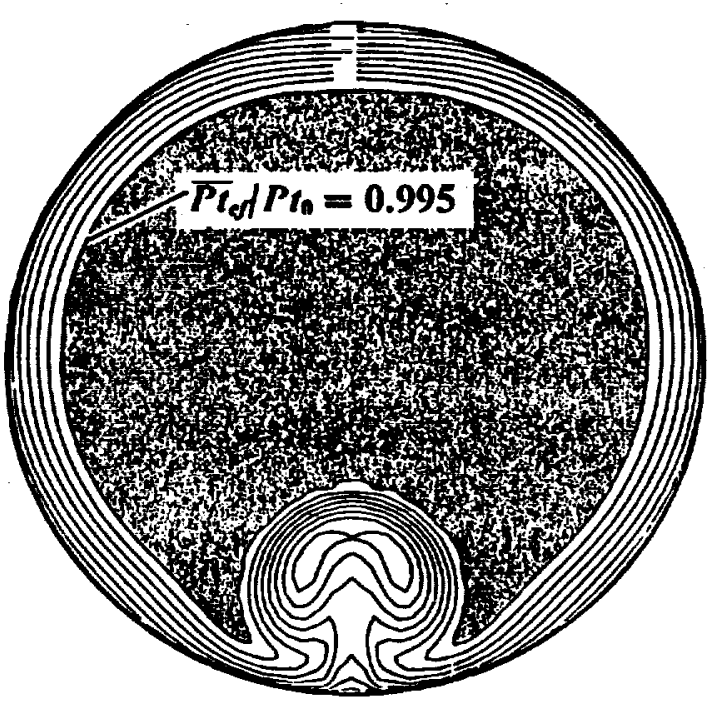

ANALYSIS

Figure (34) - Engine face total pressure contours for the 727/JT8D-100 inlet duct without vortex generators.

3 Pairs Counter-Rotating Generators

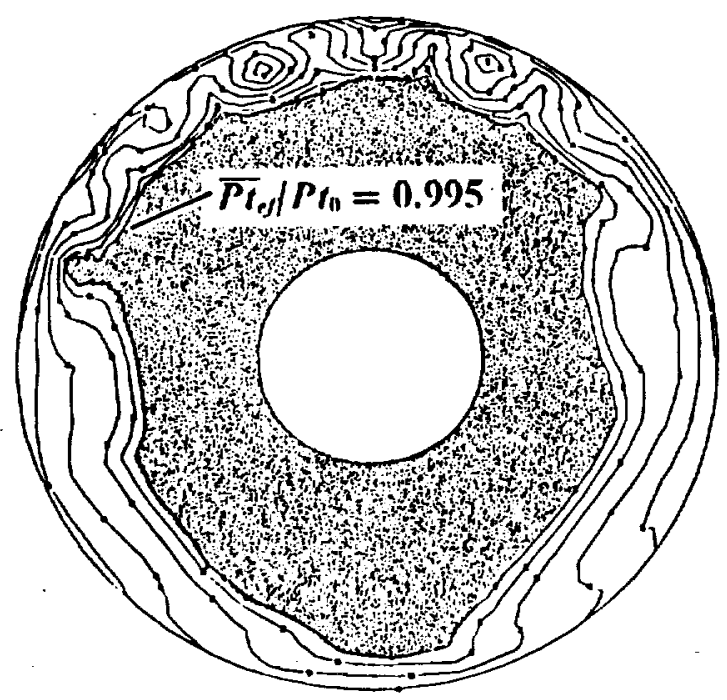

7 Pairs Co-Rotating Generators
No Counter-Rotating Generators

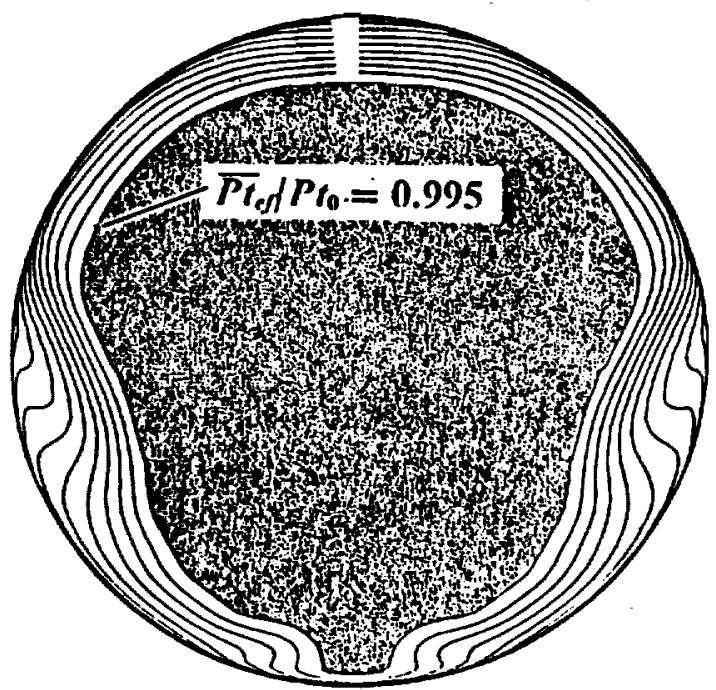

7 Pairs Co-Rotating Generators

EXPERIMENTAL DATA, CONFIG. 12

ANALYSIS, CONFIG. 3

Figure (35) - Engine face total pressure contours for the 727/JT8D-100 inlet duct with vortex generators. 


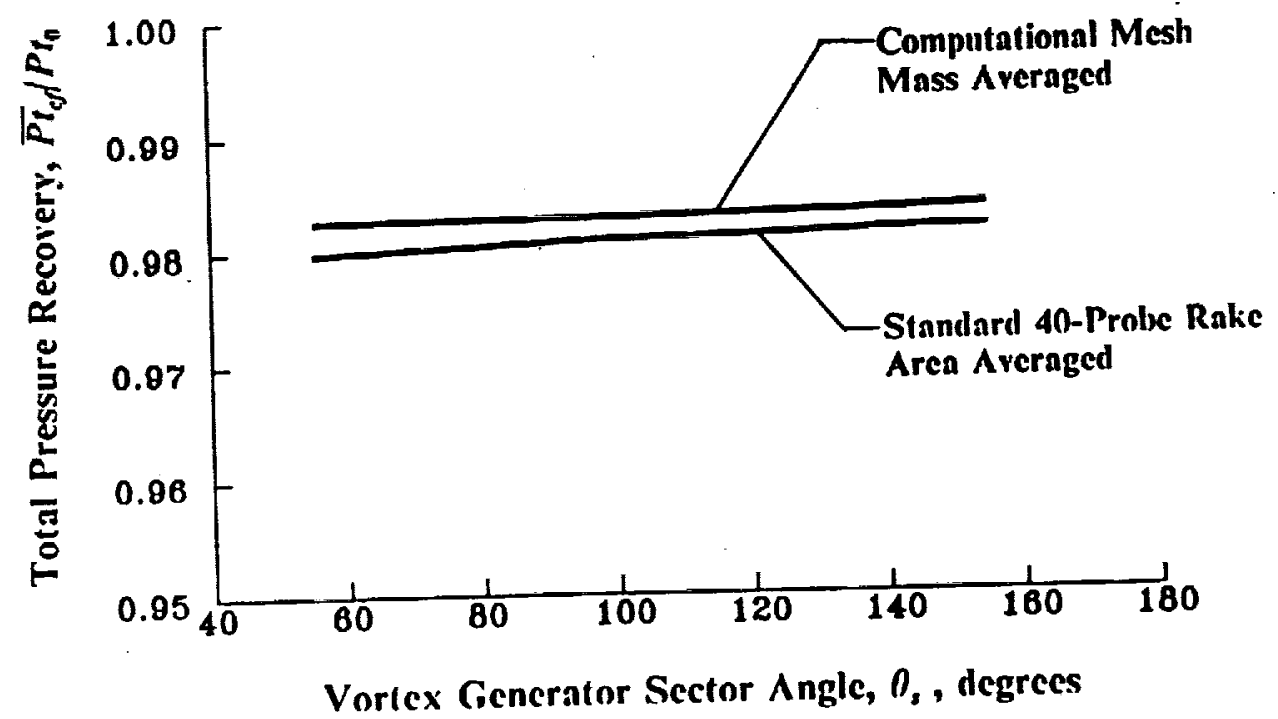

Figure (30) - Effect of vortex generator sector angle $\left(\theta_{3}\right)$ on the engine face total pressure recovery $\left(\overline{P t}_{t} f P t_{0}\right)$ at $X_{v z} / D_{i}=5.0$.

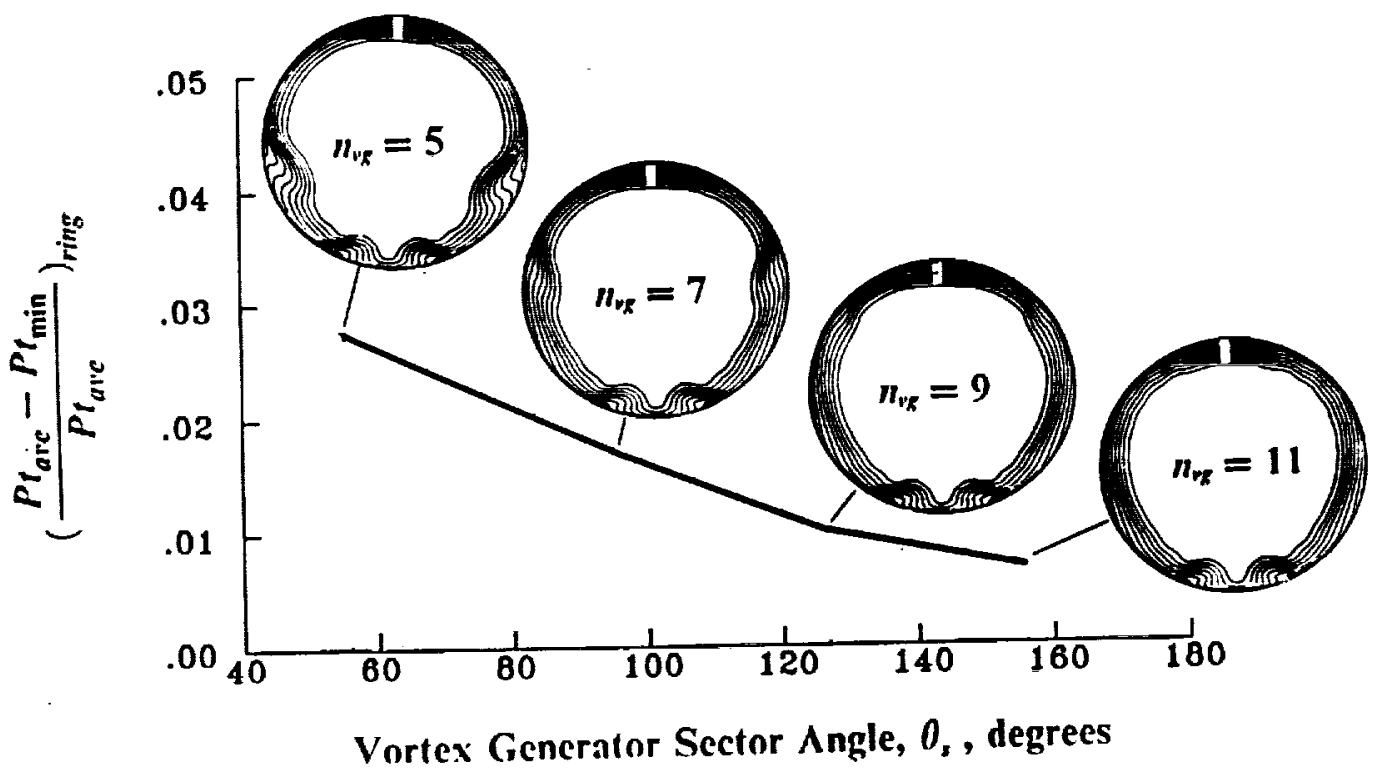

Figure (31) - Effect of vortex generator sector angle $\left(\theta_{3}\right)$ on the maximum
$60^{\circ}$-sector circumferential pressure ring distortion at $X_{r g} / R_{i}=5.0$. 


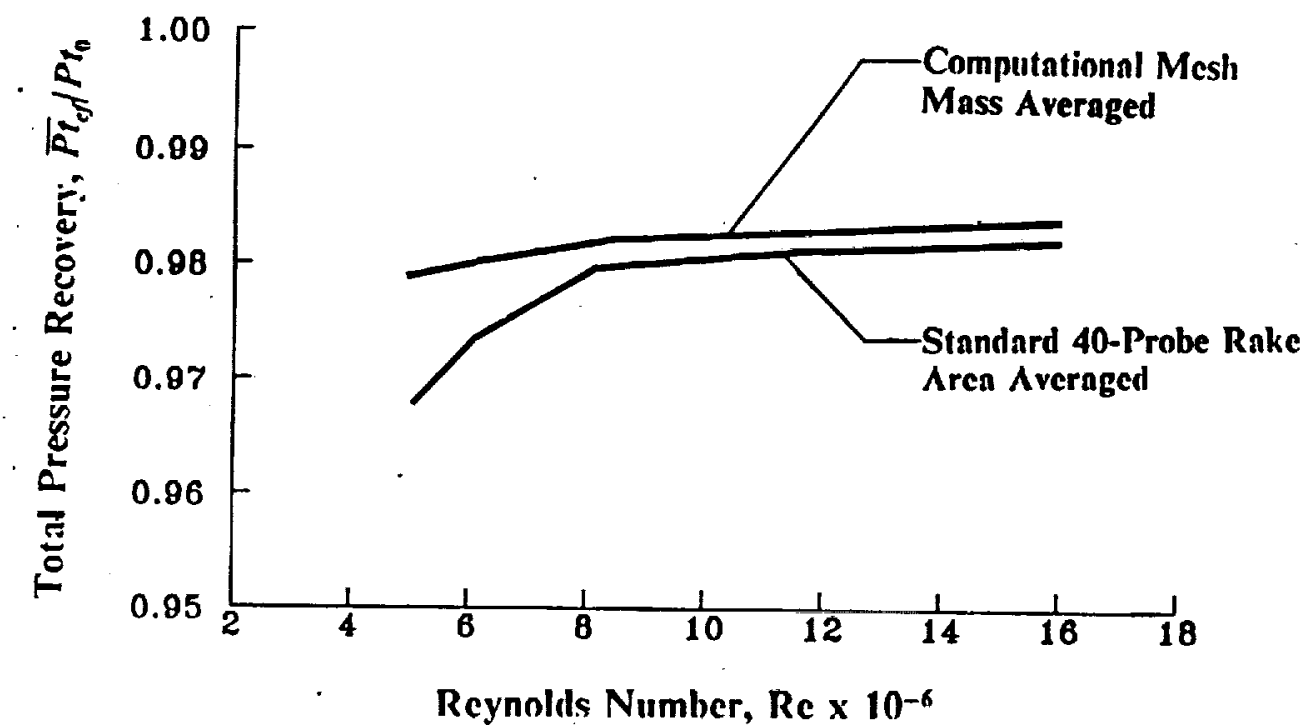

Figure (32) - Effect of Reynolds number on the engine face total pressure recovery $\left(\overline{P t_{e f}} \mid P t_{0}\right)$ at $X_{r g} / R_{i}=5.0$

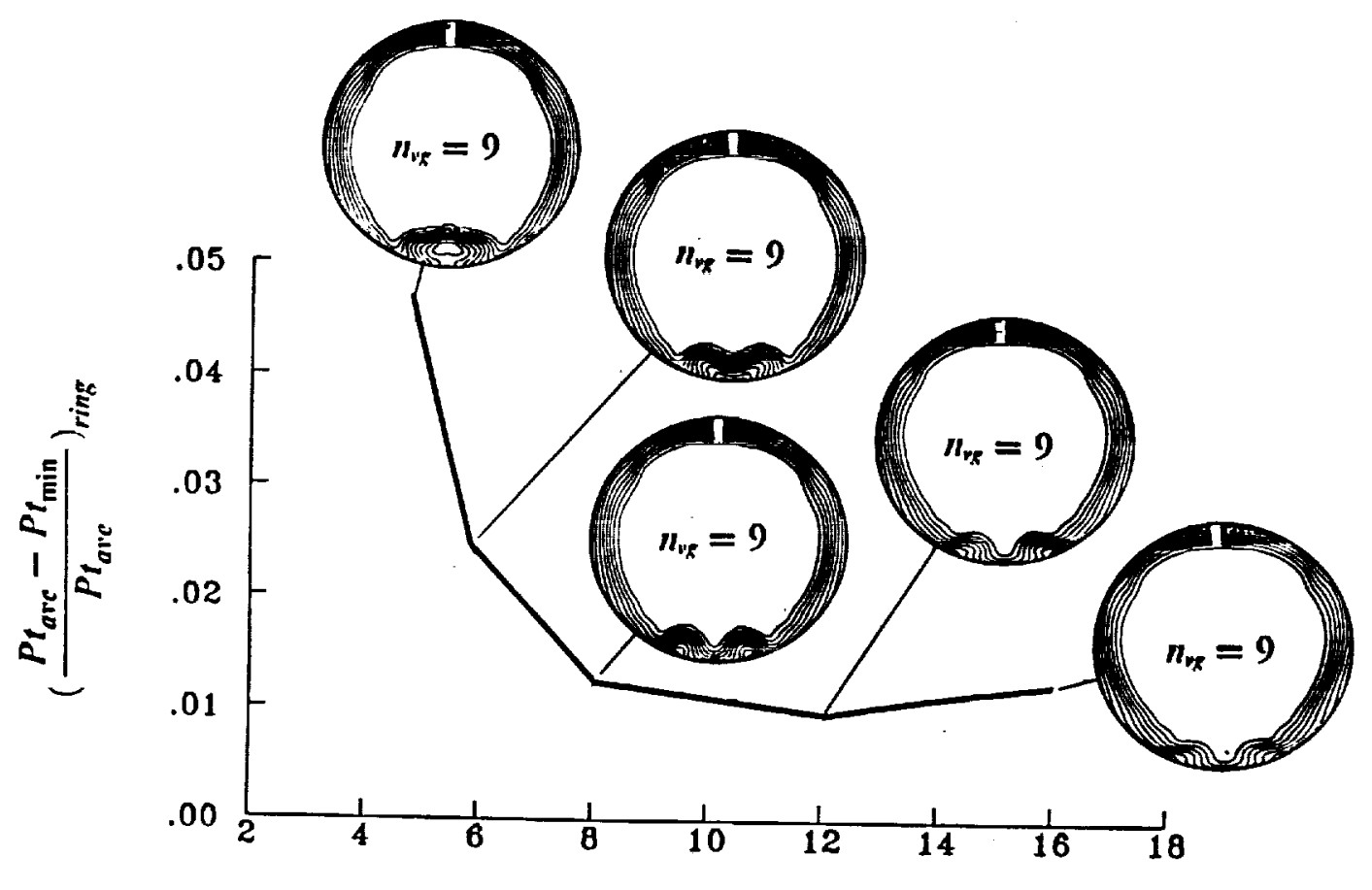

Reynolds Number, Re x 10-6

Figure (33) - Effect of Reynolds number on the maximum $60^{\circ}$-sector circumferential pressure ring distortion at $X_{y_{g}} / R_{i}=\mathbf{5 . 0}$ 
3 Pairs Counter-Rotating Generators

\section{No Counter-Rotating Generators}

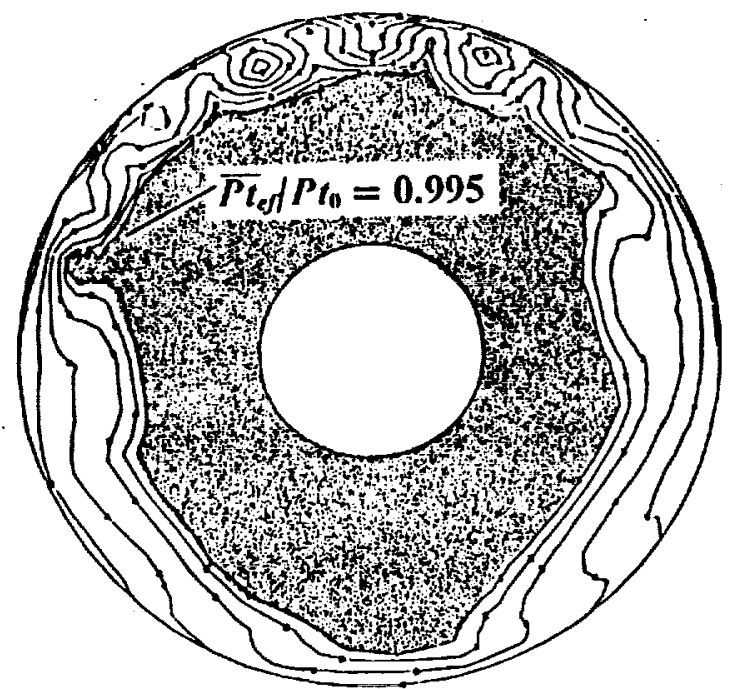

7 Pairs Co-Rotating Generators

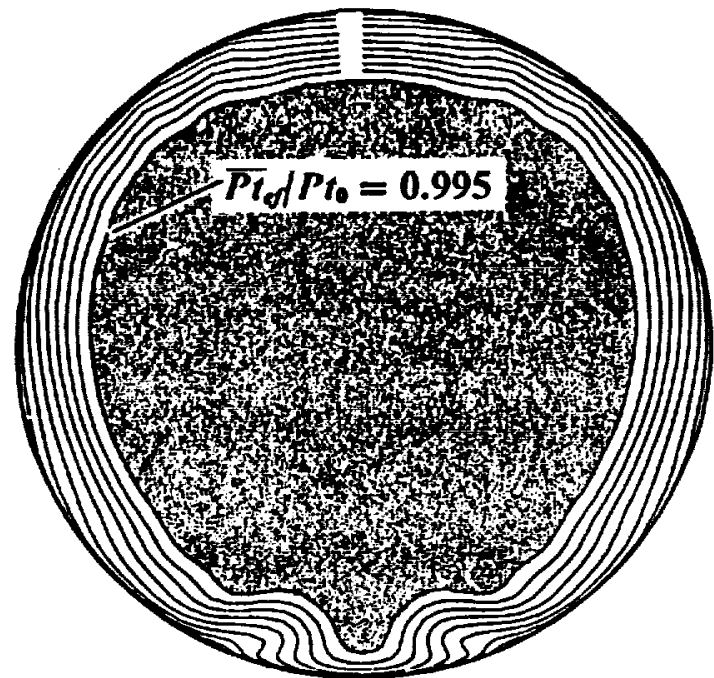

11 Pairs Co-Rotating Generators

EXPERIMENTAL DATA, CONFIG. 12

ANALYSIS, CONFIG. 15

Figure (36) - Engine face total pressure contours for the 727/JT8D-100 inlet duct with vortex generators.

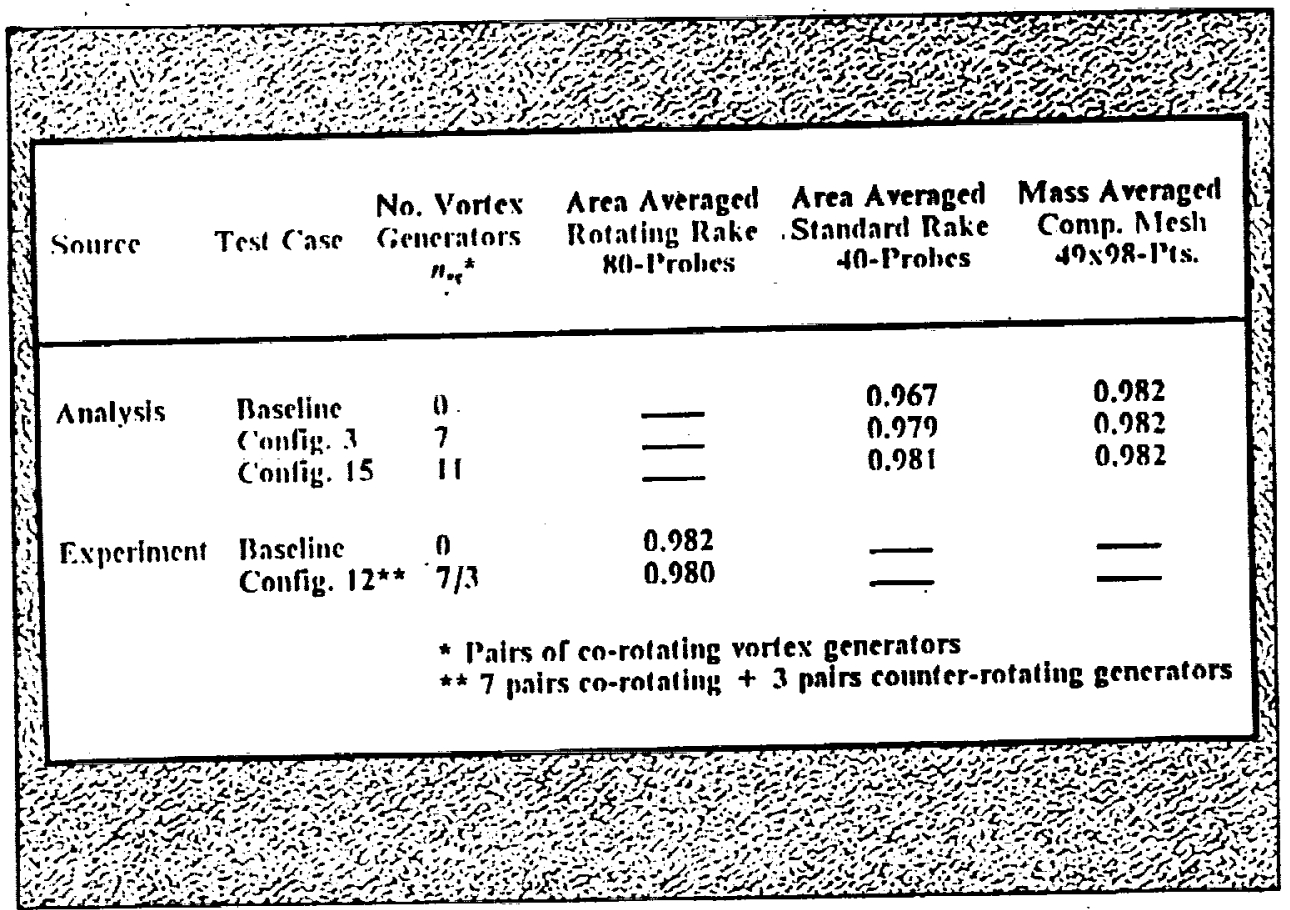

Table IV- Summary of experimental and computed engine face total pressure recovery $\left(\overline{P t_{c f}} / P t_{0}\right)$ for the $727 / \mathrm{JT8D}-100$ inlet duct. 


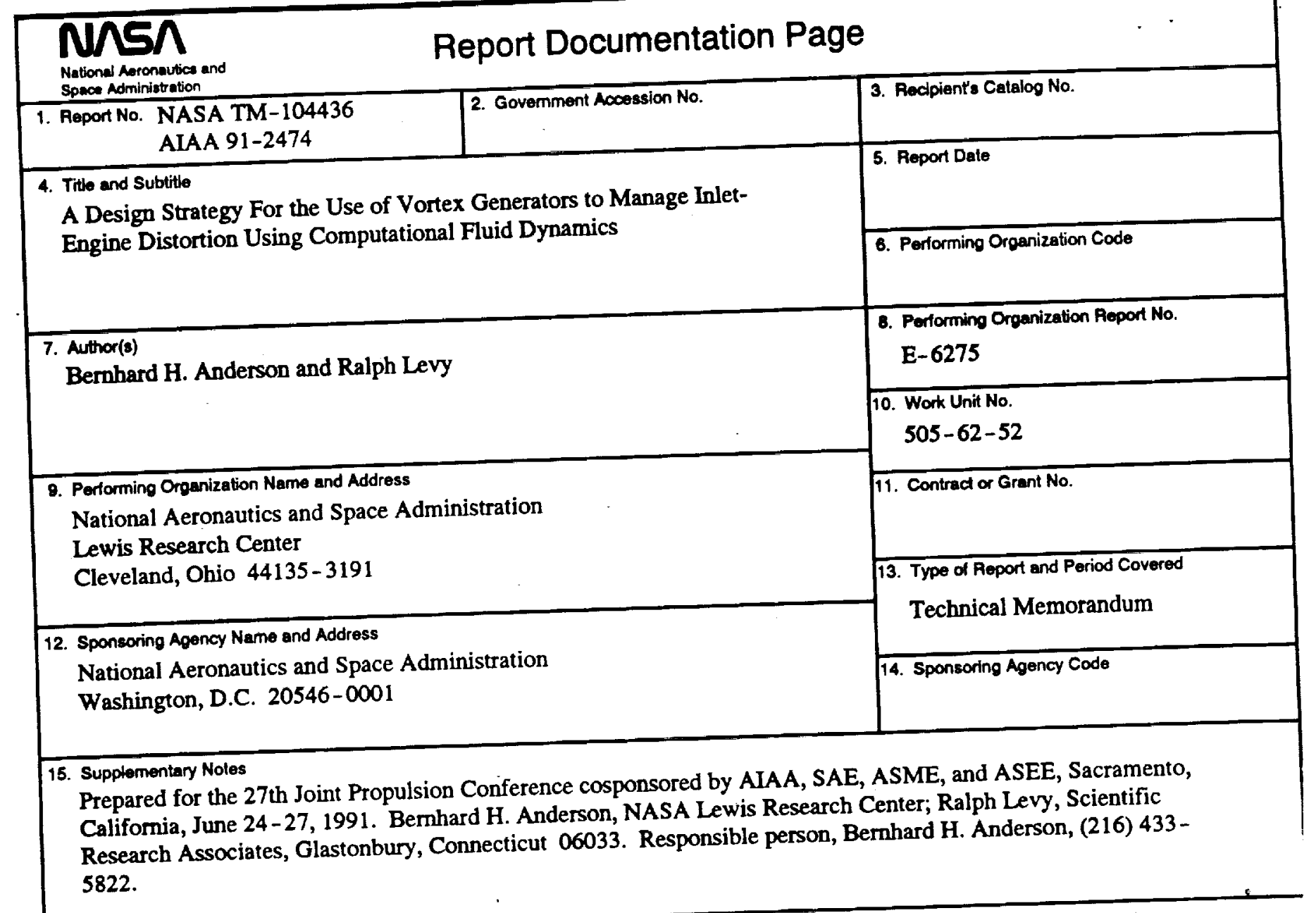

16. Abstract A Reduced Navier-Stokes solution technique has been successfollo development of secondary flow that is induced in purpose of minimizing engine face distorton by results indicate that there exists an optimum axial location for this typical three-dimensional curved inlet ducts. The within this configuration, there exists a maximum spacing between installation of co-rotating vortex generate fistortion increases rapidly. Installed vortex generator performance, as generator blades above which the engerential distortion descriptors, is sensitive to Reynolds number and thereby the generameasured by engine face cirator blade height to local boundary layer thickness. Installations of co-rotating vortex tor scale, i.e. the ratio in terms of minimizing engine face distortion within a limited range of generator scales. Hence, generators work wortex generator installations is a point design, and all other conditions are off design. In general, the loss

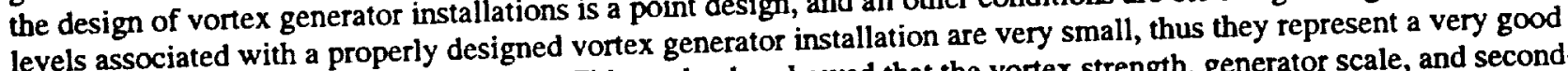
levels associated with a properiy designed This study also showed that the vortex strength, generator scale, and secondmethod to manage engine face distortion. The influence of the initial arrangement of generators.

\begin{tabular}{|c|c|c|c|}
\hline $\begin{array}{l}\text { 17. Key Words (Suggested by Author(s)) } \\
\text { Aerodynamics } \\
\text { Engine inlets } \\
\text { Computational fluid dynamics }\end{array}$ & 18. Distril & $\begin{array}{l}\text { - Unlimited } \\
\text { gory } 02\end{array}$ & \\
\hline $\begin{array}{r}\text { 18. Security Classif. (of the report) } \\
\text { Unclassified }\end{array}$ & $\begin{array}{r}\text { 20. Security Classil. (of this page) } \\
\text { Unclassified }\end{array}$ & $\begin{array}{l}\text { 21. No. of poges } \\
36\end{array}$ & $\begin{array}{r}\text { 22. Price* } \\
\text { AO3 }\end{array}$ \\
\hline
\end{tabular}


